\title{
Rochas glaciais sob o microscópio: microtexturas e microestruturas em fácies do Grupo Itararé
}

\author{
AURORA MACHADO GARCIA ${ }^{1}$, BARBARA TRZASKOS ${ }^{2}$, FERNANDO VESELY ${ }^{3}$, \\ EDUARDO DA ROSA ${ }^{4} \& \mathrm{JOHN}_{\text {ISBELL }}^{5}$ \\ ${ }^{1}$ University of Oslo, Noruega, https://orcid.org/0000-0002-5992-3614, auroramgarciaa@gmail.com \\ ${ }^{2}$ Universidade Federal do Paraná (UFPR), Curitiba, Paraná, Brasil, barbaratrzaskos@ufpr.br \\ ${ }^{3}$ Universidade Federal do Paraná (UFPR), Curitiba, Paraná, Brasil, vesely@ufpr.br \\ ${ }^{4}$ University of Wisconsin-Milwaukee (UWM), Milwaukee, WI, EUA, menozzo2@uwm.edu \\ ${ }^{5}$ University of Wisconsin-Milwaukee (UWM), Milwaukee, WI, EUA, jisbell@uwm.edu
}

\begin{abstract}
Resumo
A Era Glacial Neopaleozoica (LPIA - Late Paleozoic Ice Age) é representada na Bacia do Paraná pelo Grupo Itararé, cujos estratos fornecem um registro glacial dominado por sucessões glácio-marinhas e raros intervalos deformados por geleiras. Depósitos glaciotectonizados possuem macroestruturas como dobras, falhas e zonas de cisalhamento geradas sob ou na margem da geleira, formados quando a margem glacial avança sobre os sedimentos. Poucos estudos existem em estruturas microscópicas glaciotectônicas em estratos pré-Cenozoicos. Este estudo tem como objetivo utilizar as microestruturas como ferramenta auxiliar na interpretação de depósitos sedimentares deformados em contexto glacial. Os resultados são utilizados para avaliar criticamente a aplicabilidade da micromorfologia no registro glacial pré-pleistocênico e como essas estruturas podem ser modificadas ao longo do tempo em resposta à litificação e à diagênese. O estudo combina dados de campo com a análise micromorfológica e microestrutural detalhada de 18 lâminas petrográficas de rochas coletadas na porção basal do Grupo Itararé no município de Balsa Nova. As amostras laminadas foram coletadas em litotipos diferentes, incluindo diamictitos, arenitos e lamitos, deformados por glaciotectonismo. As microestruturas encontradas incluem uniastrial e skelsepic plasmic fabrics, foliações tipo SC, plasma bandado, estruturas rotacionais, grain turbates, alinhamento de grãos, microzonas e microplanos de cisalhamento, clastos cisalhados, falhas, dobras, 'boudins', estruturas de escape de fluidos e intraclastos. Em fácies bem selecionadas, com pouca ou nenhuma matriz, ocorrem também estruturas tipicamente relacionadas à compactação e diagênese, como grãos fraturados, redução da porosidade primária, contatos suturados e estilolitos. Os resultados mostram grande variedade de assembleias possíveis para as microestruturas, não necessariamente relacionáveis com a posição dos sedimentos em relação ao gelo no momento da deformação. Além disso, a porcentagem de matriz na amostra desempenha papel fundamental na preservação de estruturas primárias e feições de deformação em sedimentos. Fácies com pouca matriz sofrem grandes mudanças texturais devido à diagênese, que podem se sobrepor ou obliterar completamente as microestruturas glaciais.
\end{abstract}

Palavras-chave: Glaciotectônica, micromorfologia, Era Glacial Neopaleozoica.

\begin{abstract}
The Late Paleozoic Ice Age (LPIA) is recorded in the Paraná Basin as the Itararé Group, whose sedimentary rocks provide an extensive glacial record dominated by glaciomarine successions and containing rare, deformed intervals interpreted as glaciotectonites. Glaciotectonized deposits have features such as folds, faults and shear zones produced subglacially or proglacially during the advance of ice over the sediments. Few studies have addressed microscale structures related to glaciotectonic sediment deformation in the pre-Cenozoic record. This study aims to utilize microstructures as an auxiliary tool in the interpretation of sedimentary deposits formed under glacial conditions. The results were used to critically assess the applicability of micromorphology in the pre-Pleistocene glacial record, and how these structures can be modified over time in response to lithification and diagenesis. The study combines field data with detailed micromorphological and microstructural analysis on 18 thin sections of glacial rocks from the basal portion of the Itararé Group near Balsa Nova, Paraná state. Samples were collected from different lithotypes, including diamictites, sandstones, and mudstones deformed under subglacial and proglacial glaciotectonism. The microstructures include unistrial and skelsepic plasmic fabrics, SC-like foliations, banded plasma, rotational structures, grain turbates, grain alignments, microshear zones and
\end{abstract}


planes, sheared clasts, faults, folds, 'boudins', water scape structures, and intraclasts. However, well-sorted facies, which have little or no matrix, contain features typically associated with compaction and diagenesis, such as grain crushing, reduction of primary porosity, sutured contacts, and stylolites. Results suggest a large variety of possible origins for the described microstructures, not necessarily related to the position of the sediments with respect to the ice mass at the time of deposition. In addition, the percentage of matrix in the sample plays a major role in the preservation of primary sedimentary structures and soft-sediment deformation features. Facies with low matrix contents undergo major textural changes due to diagenesis, which may lead to the overlapping or complete obliteration of the glacial microstructures.

Keywords: Glaciotectonism, micromorphology, Late Paleozoic Ice Age 


\section{Introdução}

A compreensão de que deformações em sedimentos vão além de ocorrências locais, tendo significado na evolução estrutural de uma área, fez com que pesquisadores dedicassem maior atenção às morfologias estruturais em sedimentos e rochas sedimentares. Estas foram ignoradas por muito tempo devido ao foco dos estudos sobre mecânica de rochas ser em rochas deformadas em condições de alta pressão e temperatura. Estruturas formadas por deformação de sedimentos (soft-sediment deformation, SSD) refletem a transição entre condições de superfície e aquelas em maior profundidade, o que levou os cientistas a empregar princípios e métodos utilizados na mecânica dos solos, em particular a classificação de microestruturas (Maltman, 1994).

Trabalhos dedicados ao estudo da deformação relacionada à influência direta de geleiras (e.g. van de Meer 1993, van der Meer et al. 2003, van der Meer \& Menzies 2011, Phillips et al. 2011, Busfield \& Le Heron 2013, Menzies et al. 2016, Phillips et al. 2018) mostram estruturas diversas como dobras, falhas, boudins, injetitos, feições de cisalhamento, objetos rotacionados, slickensides, falhas e feições erosivas. Estas estruturas podem auxiliar na determinação do paleofluxo do gelo e da posição do material deformado em relação ao mesmo (pró- ou subglacial) a partir da distribuição vertical e horizontal das estruturas. De modo simplificado, a zona subglacial (sob a geleira) é dominada por cisalhamento simples e apresenta variação vertical ascendente positiva da intensidade da deformação, com estruturas de alto ângulo se horizontalizando conforme se aproximam da base do gelo até a completa homogeneização (van der Wateren, 2002). Já na zona proglacial (na frente da geleira) a deformação se dá principalmente por cisalhamento puro e a variação da deformação ocorre na horizontal. A parte em contato com o gelo é mais intensamente deformada, com cavalgamentos e dobras cerradas que se tornam suaves conforme se distanciam da margem da geleira (van der Wateren, 2002).

Do ponto de vista microscópico, diversos trabalhos realizados desde a década de 1990 (ver Phillips et al. 2018 e suas referências) sugerem que microestruturas possuem o potencial de auxiliar no entendimento dos processos internos que ocorrem durante a deformação de sedimentos. O reconhecimento das estruturas classificadas por van der Meer (1993) permite a diferenciação de diversos estilos deformacionais e auxilia na determinação de uma detalhada cronologia relativa para a, geralmente complexa, deformação imposta no sedimento. O estudo integrado de macro e microtramas pode ser utilizado para fornecer evidências sobre o paleofluxo do gelo (Van der Wateren et al. 2000, Menzies \& Zaniewski 2003, Vaughan-Hirsch et al. 2013), discriminar diamictitos de diferentes ambientes glaciais (Menzies et al. 2010) e para modelar o comportamento de tilitos sob stress subglacial (Brumme et al. 2019, Phillips et al. 2018).

Apesar de amplamente estudada em depósitos do Quaternário (e.g. Menzies 2012, Reinardy et al. 2015, Linch \& Van der Meer 2015, Phillips et al. 2018, Brumme et al. 2019, etc.), a micromorfologia de depósitos glaciogênicos pré-cenozoicos é raramente descrita na literatura (e.g. Denis et al. 2010, Busfield \& Le Heron 2013, Busfield \& Le Heron 2018), sendo inédita na Bacia do Paraná. O objetivo deste trabalho é documentar e avaliar a preservação de microestruturas geradas pela deformação glaciotectônica na porção basal do Grupo Itararé (Carbonífero da Bacia do Paraná), uma vez que subsequentes processos diagenéticos e tectônicos podem obliterar, ou até mesmo erradicar, o registro de tais estruturas.

\section{Métodos e contexto geológico}

Foram descritos afloramentos deformados de diamictitos, arenitos, lamitos e ritmitos do Grupo Itararé na região de Balsa Nova no Paraná, totalizando 14 exposições em uma sucessão de aproximadamente 80 metros de espessura (Fig. 1). A sucessão foi anteriormente subdivida por Rosa et al. (2019) em quatro unidades informais de acordo com características faciológicas, estratigráficas e deformacionais. Segundo os mesmos autores, essas unidades representam três ciclos glaciais (CG1, CG2 e CG3 da base para o topo) levando em consideração a intensidade da deformação e direção do paleofluxo do gelo.

De acordo com Rosa et al. (2019), a unidade 1-A pertencente ao ciclo CG1 (fluxo glacial para o Norte), sendo composta por diamictitos maciços arenosos e pobres em clastos, tendo sido depositada e deformada subglacialmente sobre os arenitos da Fm. Furnas ou rochas metamórficas do embasamento Pré-Cambriano. A unidade 1-B inferior inclui arenitos maciços e com climbing ripples, heterolitos laminados, lamitos arenosos maciços com clastos dispersos e diamictitos heterogêneos pobres em clastos. Acima desta, a unidade 1-B média abrange arenitos e conglomerados com estratificações cruzadas, diamictitos maciços em conjunto com arenitos com climbing ripples, heterolitos laminados, lamitos arenosos com clastos dispersos e diamictitos ricos em clastos. $\mathrm{O}$ conjunto das unidades 1-B inferior e média compõem o ciclo CG2, em que a deposição ocorreu em contexto glaciomarginal a pró-glacial (em leques proximais e distais) e deformadas proglacialmente pelo avanço da geleira para oeste. Por último, a unidade 1-B superior compreende arenitos e conglomerados com estratificações cruzadas, arenitos maciços e com climbing ripples, diamictitos arenosos maciços ricos em clastos e conglomerados maciços. Esta unidade representa o terceiro ciclo glacial, CG3, onde as rochas também foram depositadas em contexto glaciomarginal e deformadas pró- e subglacialmente por geleira avançando para noroeste.

Para este trabalho, descrevemos e medimos detalhadamente estruturas deformacionais em escala de afloramento e de amostra de mão, tais como dobras, falhas e planos de cisalhamento, além de amostras orientadas de fácies deformadas e indeformadas para a confecção de lâminas petrográficas. No total, 19 seções delgadas foram feitas de seis afloramentos distintos (tabela 1), priorizando rochas deformadas que apresentavam alto potencial para exibirem microtexturas e microestruturas como as descritas em depósitos quaternários. 


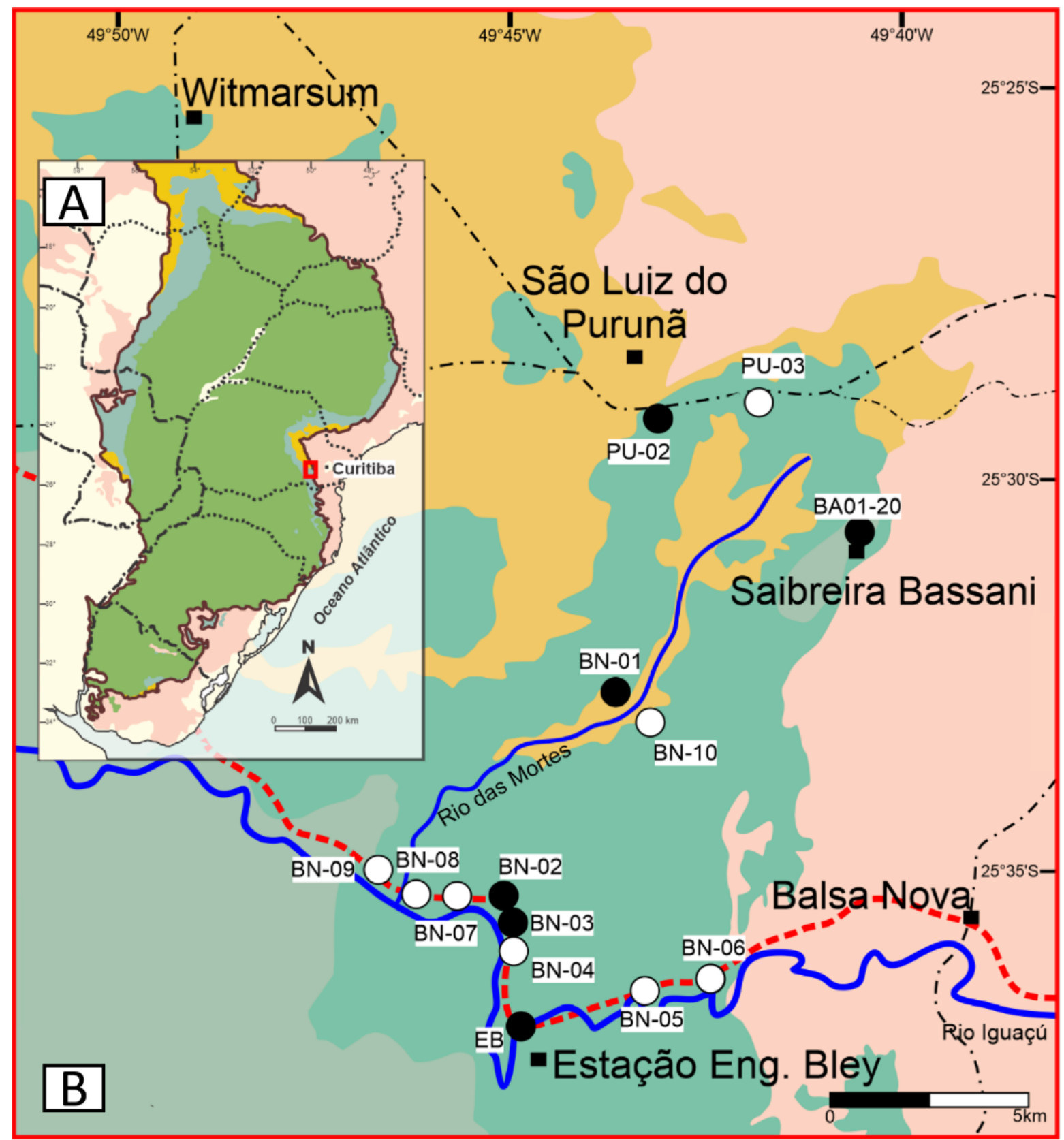

\section{Simbologia}

$\square$ Área de estudo

Afloramento

- Afloramento com lâmina

.-. Rodovia

..- Ferrovia

Rio

\section{Estratigrafia}

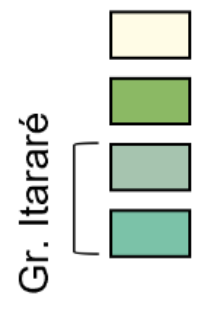

Coberturas cenozoicas

Permiano nferior ao Cretáceo

Fm. Lagoa Azul superior (depósitos proglaciais)

Fm. Lagoa Azul inferior (depósitos subglaciais e glácio-marginais)

Formação Furnas (Devoniano)

Embasamento cristalino

Figura 1 - Localização e contexto geológico. A) Mapa da Bacia do Paraná com localização da área de estudo (retângulo vermelho). B) Mapa geológico da região estudada com indicação dos afloramentos examinados (geologia de acordo com Rosa et al., 2019). 


\begin{tabular}{|c|c|l|}
\hline Afloramento & Lâmina & \multicolumn{1}{c|}{ Litologia } \\
\hline PU-02 & PU02 & $\begin{array}{l}\text { Diamictito com matriz arenosa, pobre em clastos. Apresenta } \\
\text { planos de cisalhamento sub-horizontais com espaçamento cm. }\end{array}$ \\
\hline BN-01 & BN01 & Diamictito maciço com matriz arenosa, rico em clastos. \\
\hline BN-02 & $\begin{array}{c}\text { BN02-1, BN02-2, } \\
\text { BN02-4 }\end{array}$ & $\begin{array}{l}\text { Arenito fino bem selecionado com camadas de arenito médio } \\
\text { a grosso. Possuem lineações e planos de cisalhamento com } \\
\text { espaçamento mm a cm. }\end{array}$ \\
\hline BN-03 & BN03 & $\begin{array}{l}\text { Arenito fino com níveis micáceos. Possui planos de cisalhamento } \\
\text { com espaçamento mm. }\end{array}$ \\
\hline EB & $\begin{array}{c}\text { EB07 (A e B), } \\
\text { EB10 (A e B), EB11 }\end{array}$ & $\begin{array}{l}\text { Arenito bem selecionado, variando de muito fino a médio. Possui } \\
\text { escassos planos de cisalhamento com espaçamento cm. }\end{array}$ \\
\hline BA & $\begin{array}{c}\text { BA01, BA05, BA06, } \\
\text { BA10, BA11, BA20, } \\
\text { BA21, BA23 }\end{array}$ & $\begin{array}{l}\text { Diamictitos lamosos a arenosos, pobre em clastos (com planos } \\
\text { de cisalhamento com espaçamento cm); diamictitos arenosos } \\
\text { maciços ricos em clastos; arenitos lamosos a médios, bem } \\
\text { selecionados e comumente maciços, mas com ocasionais planos } \\
\text { de cisalhamento. }\end{array}$ \\
\hline
\end{tabular}

Tabela 1 - Relação dos afloramentos e lâminas descritos neste trabalho (ver figura 1 para localização).

As lâminas foram confeccionadas segundo o plano $\mathrm{AC}$ de deformação, ou seja, paralelas ao paleofluxo do gelo ou à direção de maior strain (identificada por meio de lineações e geralmente coincidente com a direção do paleofluxo do gelo) de modo a exibir estruturas indicadoras da cinemática da deformação. A descrição microscópica foi focada em identificar e distinguir as microfeições apresentadas na classificação proposta por Van der Meer (1993) (Fig. 2). Para isto, utilizou-se diferentes iluminações e filtros na lâmina (falsa cor) para destacar certas estruturas, principalmente as microtramas do plasma (plasmic fabrics) e planos de cisalhamento com concentração de argila e/ou óxidos (Fig. 3).

\section{Resultados}

\subsection{Macroscopia}

Em campo e em amostras de mão, os planos de cisalhamento são descritos como contínuos, anastomosados e ondulados nos três ciclos glaciais definidos por Rosa et al. (2019) e Vesely et al. (2015) (Fig. 4A). Tais planos são observados em diferentes escalas e litotipos apesar de se desenvolverem com mais facilidade em rochas ricas em argila na forma de planos com espaçamento milimétrico a centimétrico, em padrão anastomosado a curtas distâncias. Em arenitos e diamictitos arenosos são formadas zonas de cisalhamento de até $60 \mathrm{~cm}$ de espessura (Fig. 4B), caracterizadas por diversos planos fortemente deformados. Nestas áreas, rochas cataclásticas, que geralmente estão mais intemperizadas, contêm raros indicadores cinemáticos (Fig. 4C), tais como estepes. Em níveis predominantemente argilosos, deformação dúctil é observada, com lentes de areia boudinadas e discretos planos de cisalhamento que distorcem estruturas primárias, tais como laminações e estratificações.
No total, 233 planos de cisalhamento foram medidos em campo e agrupados de acordo com os ciclos glaciais propostos por Rosa et al. (2019).

Grandes falhas de empurrão e zonas de cisalhamento ocorrem na saibreira Bassani (Fig. 1B), encontradas em arenitos cascalhosos e diamictitos arenosos (Fig. 4D). As falhas apresentam características irregulares, com planos ondulados anastomosados ao longo do afloramento. Apesar de raras, lineações podem ser encontradas em alguns planos (Fig. 4C). Falhas normais são encontradas em diversos afloramentos e em escalas variadas. Raramente formam planos bem desenvolvidos, sendo identificadas a partir do deslocamento de estruturas primárias parcialmente preservadas (Fig. 5A). Estruturas do tipo boudin são observadas em arenitos mal selecionados e maciços, em contato com diamictitos arenosos estratificados (Fig. $5 \mathrm{~B}$ e C). Por vezes, estruturas morfologicamente semelhantes a sombras de pressão (porém sem recristalização nas caudas) ocorrem em volta de seixos, podendo ser utilizadas como indicadores cinemáticos (Fig. 5D).

Foram ainda identificadas dobras com comprimento de onda de até $15 \mathrm{~m}$ em exposições de diamictitos arenosos (Fig. 6A), além de dobras menores e com menor ângulo entre flancos em rochas mais finas, especialmente lamitos, variando de poucos centímetros até alguns metros. Dobras também são observadas em associação com falhas de empurrão, tais como dobras de arrasto, dobras em bainha e dobras sem raízes (Fig. 6B).

\subsection{Microscopia}

O desenvolvimento de feições associadas à deformação glaciotectônica nas rochas do Grupo Itararé não se restringe à deformação em escala macroscópica. Ao todo, 21 microfeições diferentes, relacionadas a processos deformacionais e diagenéticos (estruturas e texturas), foram identificadas em lâmina (tabela 2). 


\section{Microtramas e microestruturas em Plasma e $S$-matrix de sedimentos glaciais}

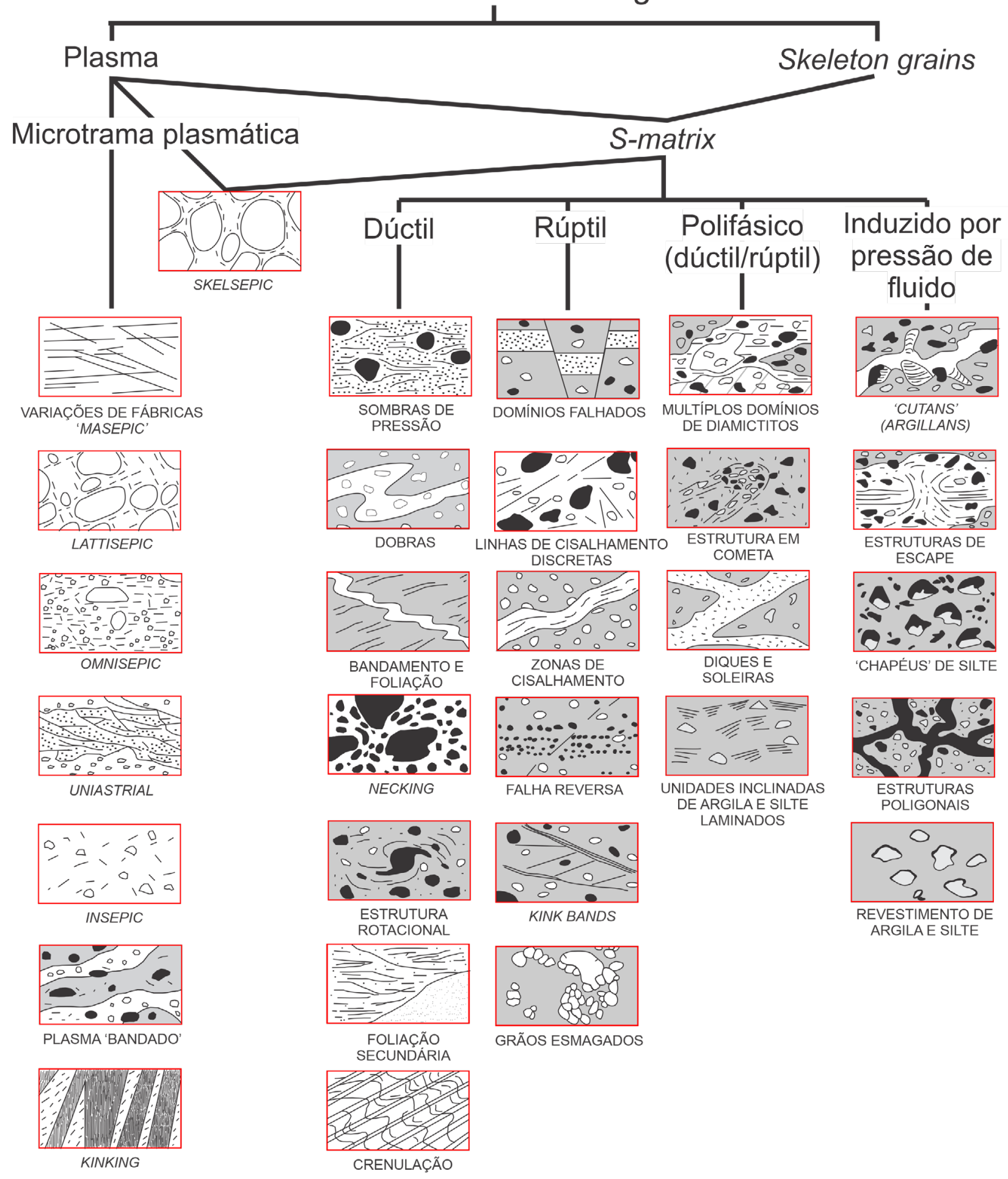

Figura 2 - Classificação de microtramas e microestruturas proposta por Van der Meer (1993). Adaptado de Van der Meer \& Menzies (2011). 

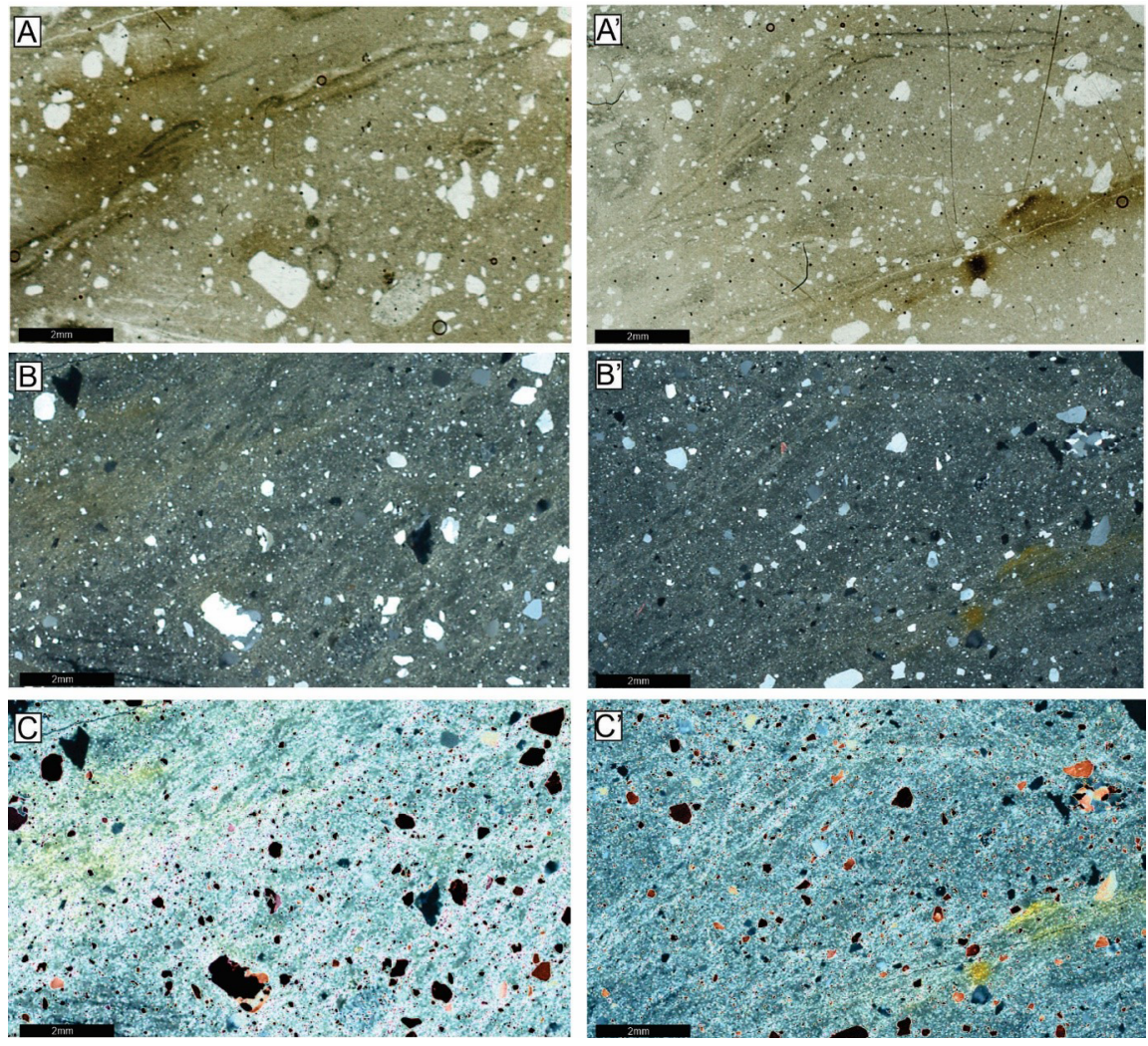

Figura 3 - Imagens ilustrando as diferentes iluminações utilizadas para destacar orientações da microtrama das amostras. Fotomicrografias da amostra BA-10. (A e A') Polarizadores paralelos. (B e B') Polarizadores cruzados. (C e C') Polarizadores cruzados sobrepostos por filtros falsa cor.

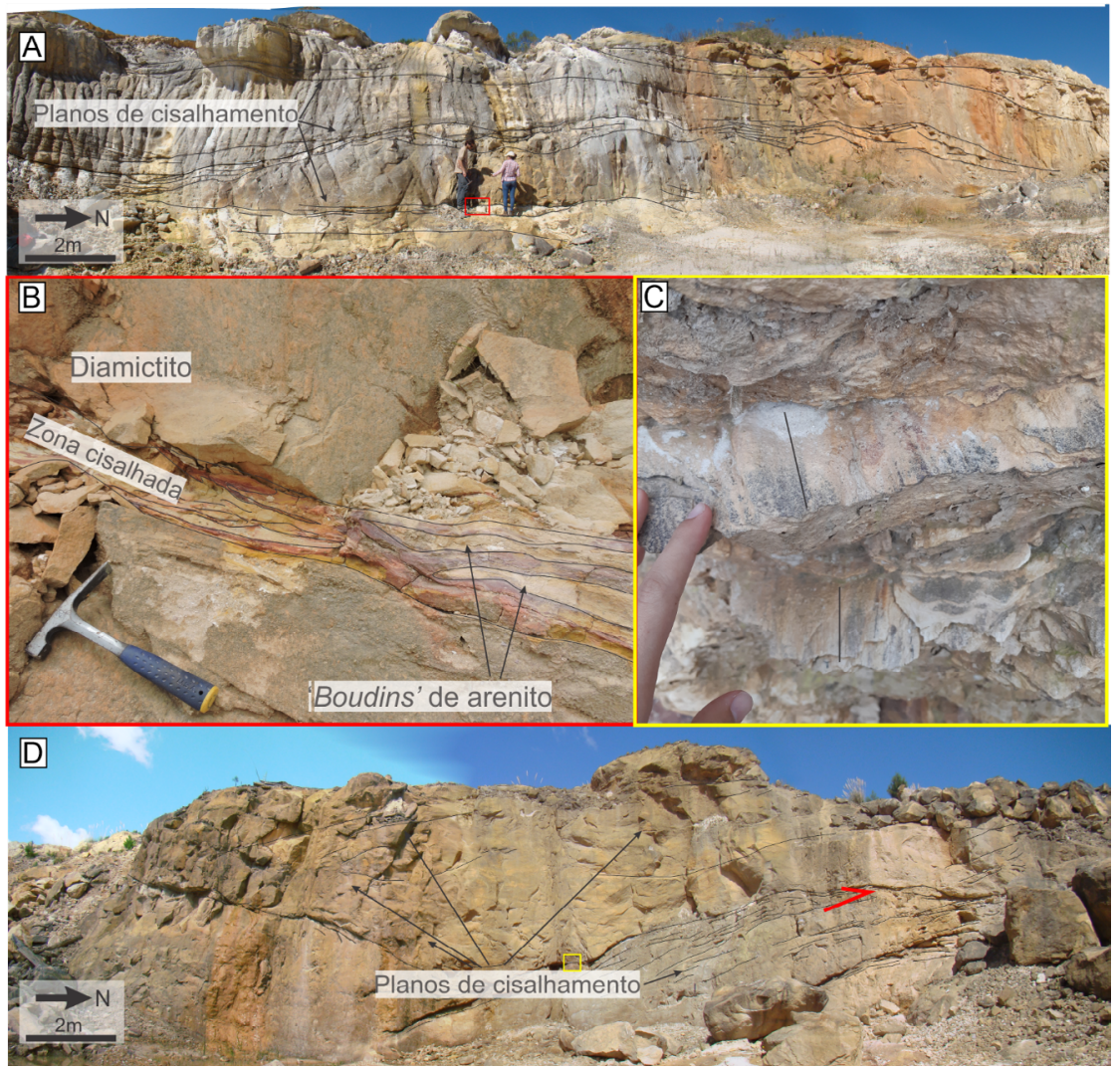

Figura 4 - Estruturas glaciotectônicas na saibreira Bassani (BA01-20). (A) Planos ondulados de cisalhamento em diamictitos arenosos com detalhe (retângulo vermelho) para (B) zona de cisalhamento com concentração da deformação em fácies de matriz argilosa com lentes "boudinadas" de areia. (C) Detalhe (retângulo amarelo em D) de planos estriados encontrados em afloramento de arenito deformado (D). 

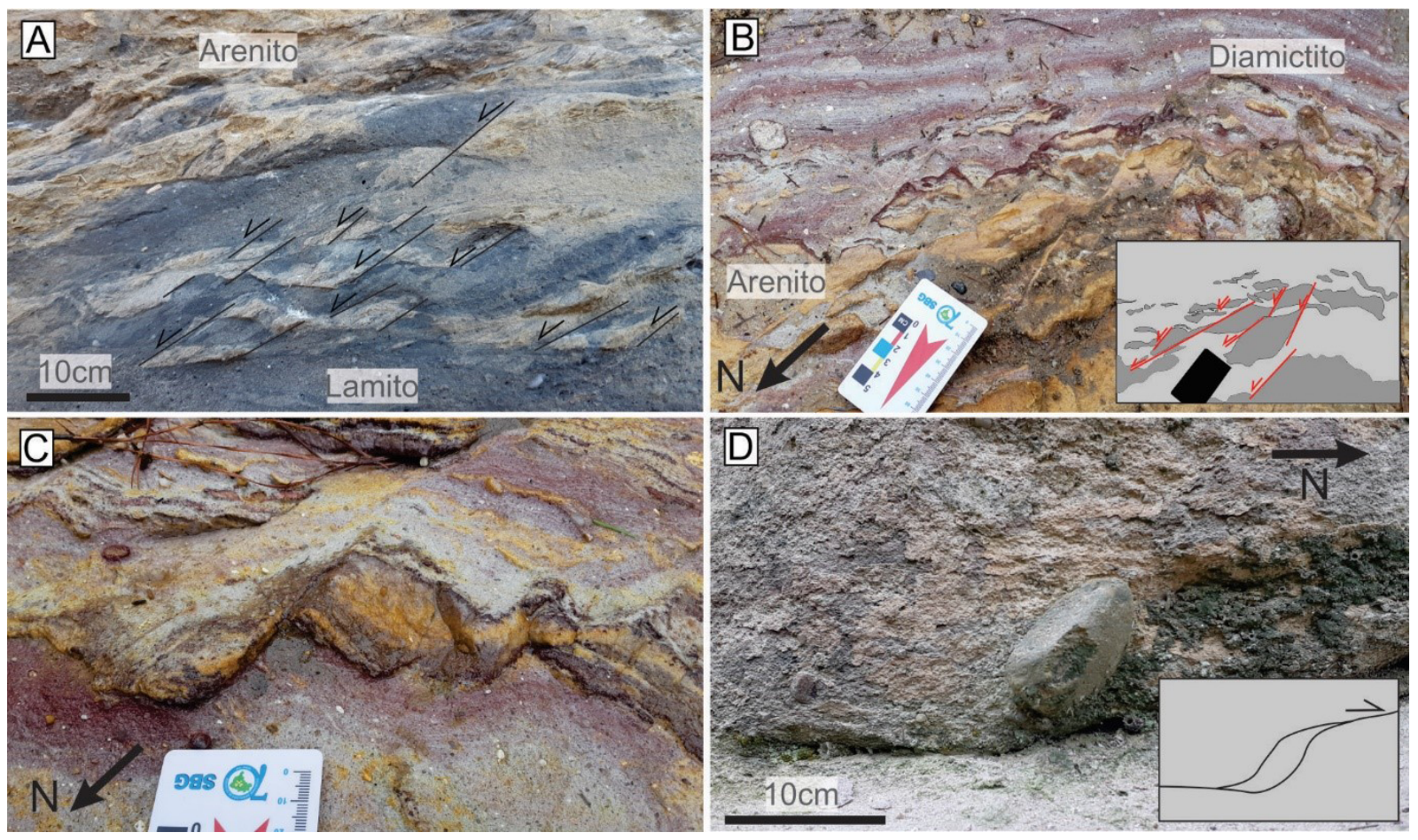

Figura 5 - Estruturas encontradas em afloramento. (A) Falhas normais em heterolito do afloramento BN-04. (B) Estruturas do tipo boudin em arenito em contato com diamictitos do afloramento BN-01. (C) Detalhe do boudin do afloramento BN-01 com falhas normais deformando as lentes de areia. (D) Pseudo-sombra de pressão formada ao redor de clasto do afloramento BN-08.
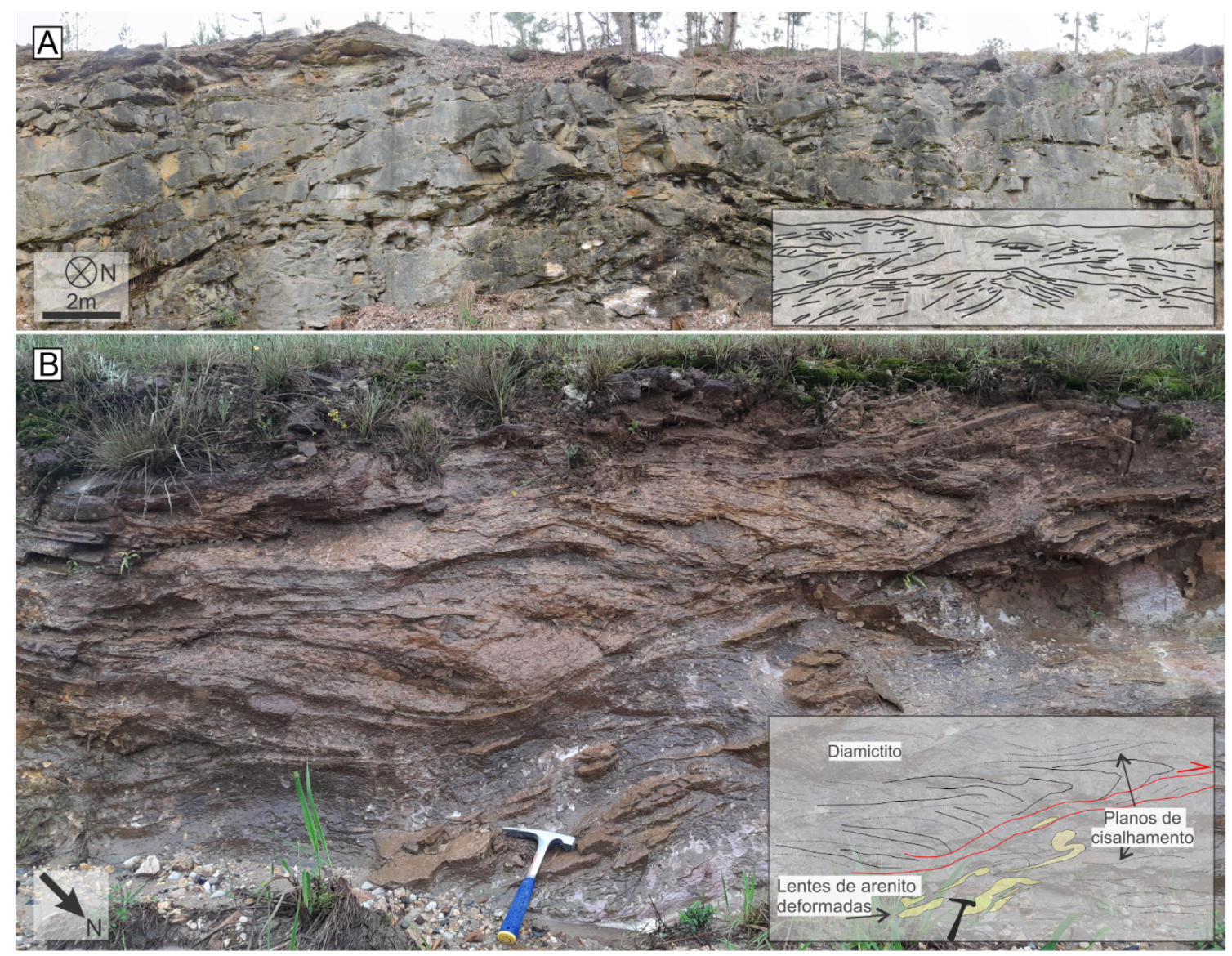

Figura 6 - Dobras. (A) Dobra suave em arenitos do afloramento EB. (B) Dobra de arrasto associada a falha inversa em diamictitos no afloramento BN01. Notar as lentes de areia deformadas na parte inferior da exposição. 


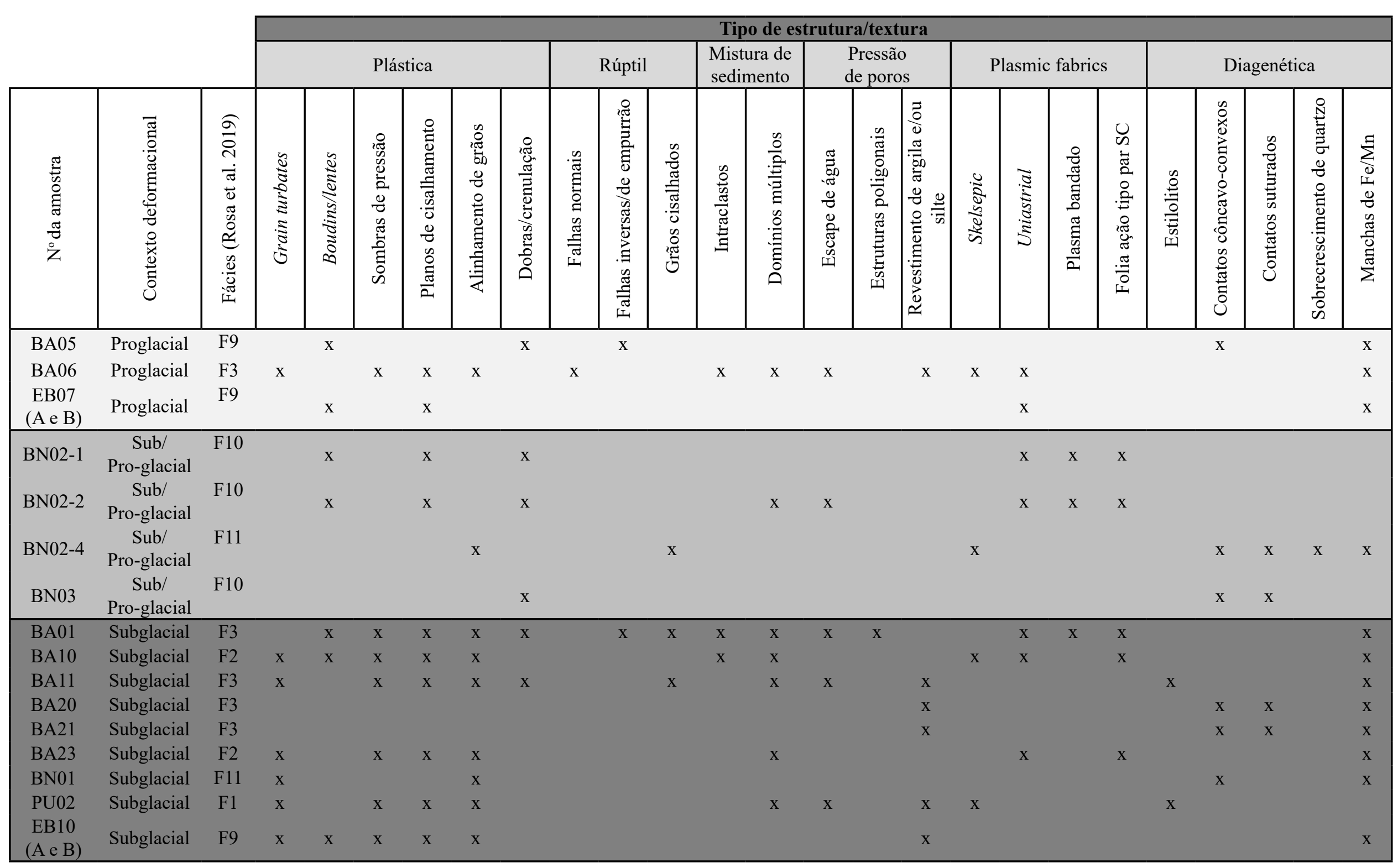

Tabela 2 - Relação das estruturas e texturas encontradas em cada amostra e seu respectivo ambiente de formação. 
Diamictitos maciços em amostra de mão, salvo presença de discretos planos de cisalhamento, podem apresentar extensa gama de estruturas e texturas quando vistos sob o microscópio. É o caso de amostras PU02 (Fig. 7), BA11 (Fig. 8), BA06 (Fig. 9), onde apenas com o escaneamento da lâmina é possível distinguir feições como alinhamento de grãos, estilolitos, lentes de areia deformadas, pseudo-sombras de pressão, grãos cisalhados, grain turbates, planos de cisalhamento e a composição de clastos.

Em amostras estratificadas, como a BA06, foram observados diferentes tipos de estruturas dependendo da camada (Fig. 9). As porções de granulação mais fina desenvolvem planos de cisalhamento e plasmic fabrics com facilidade, enquanto estruturas formadas por orientação dos grãos (seja linear ou curva ao redor de outros grãos - grain alignments) são observadas nas camadas areno-cascalhosas.

Com estilo rúptil e dúctil, zonas e planos de cisalhamento são encontrados em grande parte das lâminas descritas (Fig. 10A e B), apesar de se desenvolverem melhor em amostras com teor de argila mais elevado. Ramificações e fusões dos planos são comuns, com concentração de óxidos e argilas nos planos, destacando-os. Frequentemente, os planos passam por clastos, que mudam sua orientação (strain caps) ou formam "sombras de pressão", apresentando estilo dúctil. Zonas de cisalhamento rúpteis também podem afetar os clastos diretamente, fragmentando-os em porções com alta angulosidade e baixa esfericidade (Fig. 10C).
Foliações do tipo par SC (Fig. 10D) e plasmic fabrics, subdividas entre skelsepic, uniastrial (Fig. 10E) e plasma bandado, de acordo com o grau de desenvolvimento da estrutura, são caracterizadas em lâmina a partir da orientação de filossilicatos detríticos e material fino. Quando encontram objetos rígidos, como clastos, a trama tende a contorná-los, gerando "sombras de pressão" geralmente assimétricas (Fig. 10F), que podem ser utilizadas como indicadores cinemáticos. Outros indicadores cinemáticos que podem ser descritos são as micas deformadas do tipo fish (Fig. 10G).

As plasmic fabrics, que são morfologicamente foliações (porém sem a recristalização dos filossilicatos), por vezes podem ser associadas a planos observados em afloramento (Fig. 11A e B). Em lâmina (Fig. 11C), os planos com baixo ângulo de mergulho são definidos por micas orientadas, que contornam clastos ao encontrá-los, às vezes gerando sombras de pressão. Já os planos oblíquos aparecem como clivagens de fratura, sem minerais definindo sua orientação, cortando os filossilicatos orientados.

Diferentes estilos de dobramentos foram descritos, tais como dobras em bainha, fechadas a cerradas, dobras parasíticas e dobras de arrasto (Fig. 12A e B). Elas também podem ser encontradas em associação com outras estruturas, especialmente falhas e boudins, como arrastos próximos a ruptura das camadas (Fig. 12C). Essas inflexões foram observadas tanto em rochas arenosas quanto lamosas, com maior abundância naquelas que possuíam laminação sedimentar parcialmente preservada.
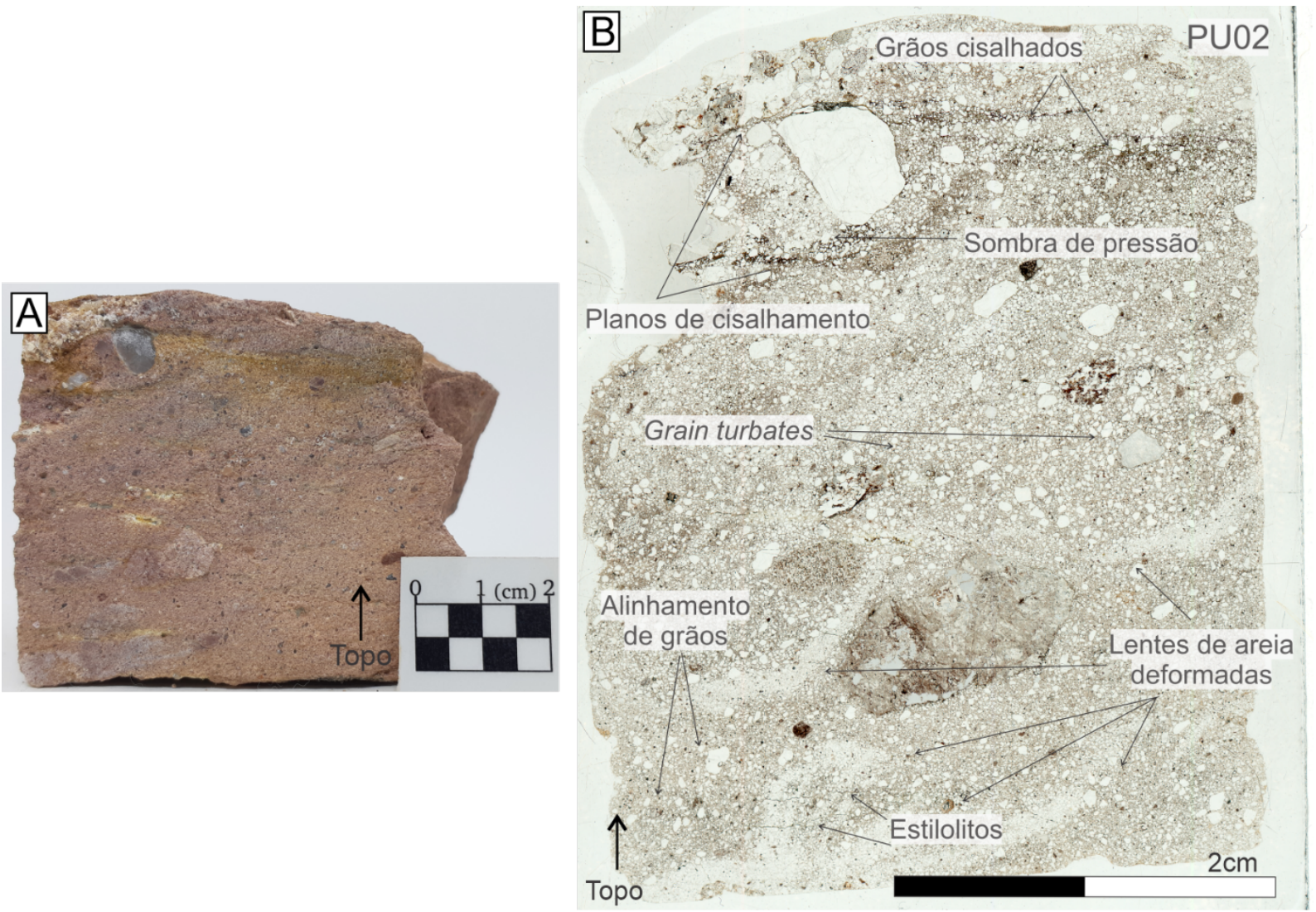

Figura 7 - (A) Amostra de diamictito PU-02. Retângulo vermelho indica posição da lâmina. (B) Imagem digital (obtida com scanner) da seção delgada com indicação de algumas das estruturas encontradas. 

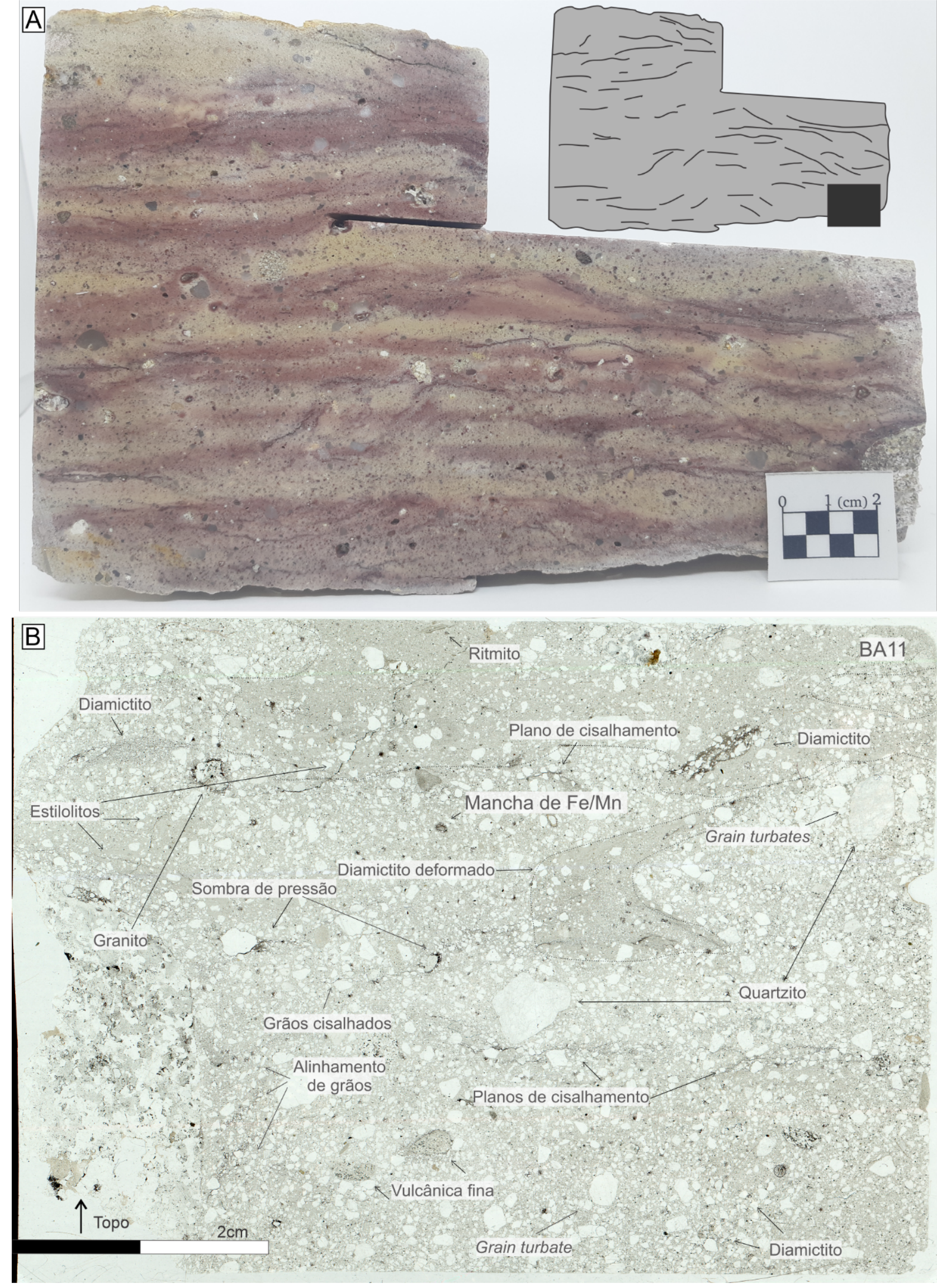

Figura 8 - (A) Amostra de diamictito BA11. Esquema no canto superior direito ressalta planos de cisalhamento. (B) Imagem digital da seção delgada com indicação de algumas das estruturas e composições de clastos encontrados. 

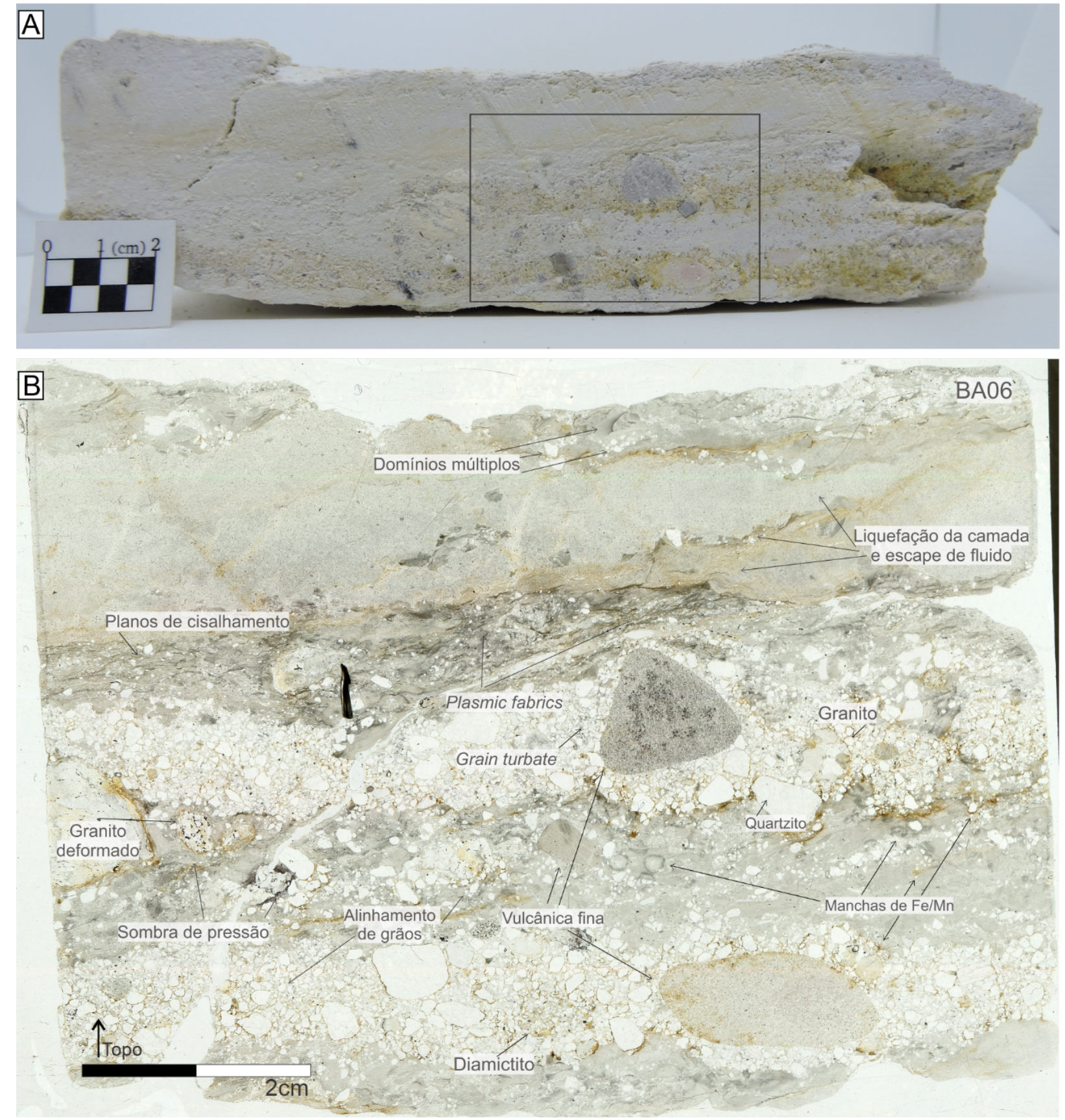

Figura 9 - (A) Diamictito estratificado da amostra BA06. Retângulo preto indica posição da lâmina. (B) Imagem digital da seção delgada com indicação de algumas das estruturas e composições de clastos encontrados.

Falhas normais e inversas, observadas em lâmina, atuam como agentes que rompem ou obliteram laminações sedimentares. Apesar de não formarem planos bem desenvolvidos, em alguns casos é possível observar smear entre as camadas afetadas (tanto de argila quanto de areia), com sutil mudança de orientação dos grãos. $\mathrm{O}$ falhamento de camadas menos competentes em contato com camadas competentes comumente gera estruturas morfologicamente similares a boudins.

Grande parte dos diamictitos lamosos possui estruturas formadas por rotação. Grain turbates são descritos em abundância, onde grãos menores formam alinhamento circular ou em espiral ao redor de clastos maiores
(Fig. 13A e B). Além da orientação curvilínea de grãos, alinhamentos lineares são abundantes em diamictitos (Fig. 13C e D).

Evidências de escape de água são raras. Os caminhos formados são geralmente muito sutis, contendo pequenas mudanças na orientação dos grãos (em direção ao topo). Por vezes são observadas injeções de areia interrompendo camadas. A liquefação de porções da amostra laminada pode ser observada raramente, como no caso da amostra BA06 (Fig. 9B). Outras feições relacionadas a pressão de poros são mais comuns, como domínios múltiplos e revestimentos de clastos por silte e argila. Estruturas poligonais são raras. 

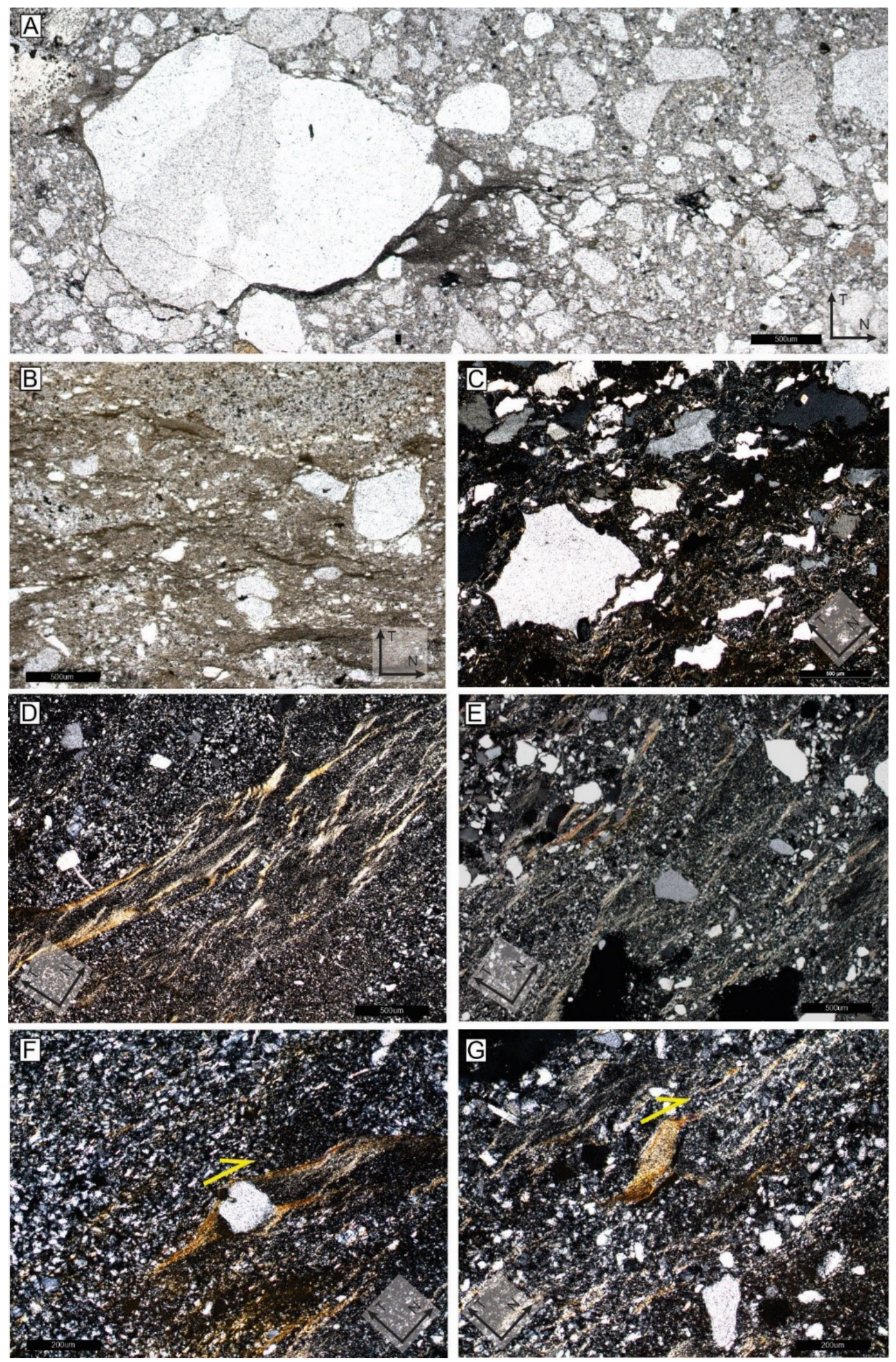

Figura 10 - Fotomicrografias de amostras deformadas. (A) Planos de cisalhamento com concentração de argila contornando grão de quartzo e gerando sombra de pressão (amostra BA11). (B) Planos de cisalhamento contornando e quebrando grãos (amostra BA06). (C) Grãos de quartzo intensamente cisalhados com pouco ou nenhum retrabalhamento (amostra BA01). (D) Sombra de pressão formada por plasmic fabric uniastrial ao encontrar um grão de quartzo (amostra BA06). Mica fish na amostra BA06. (E e F) Sombra de pressão ao redor de clasto de quartzo (amostra BA06). (G) Mica tipo fish na amostra BA06 indicando movimento dextral. Barra de escala corresponde à $500 \mu m$ nas figuras A-E e $200 \mu \mathrm{m}$ nas figuras $\mathrm{F}$ e G. 

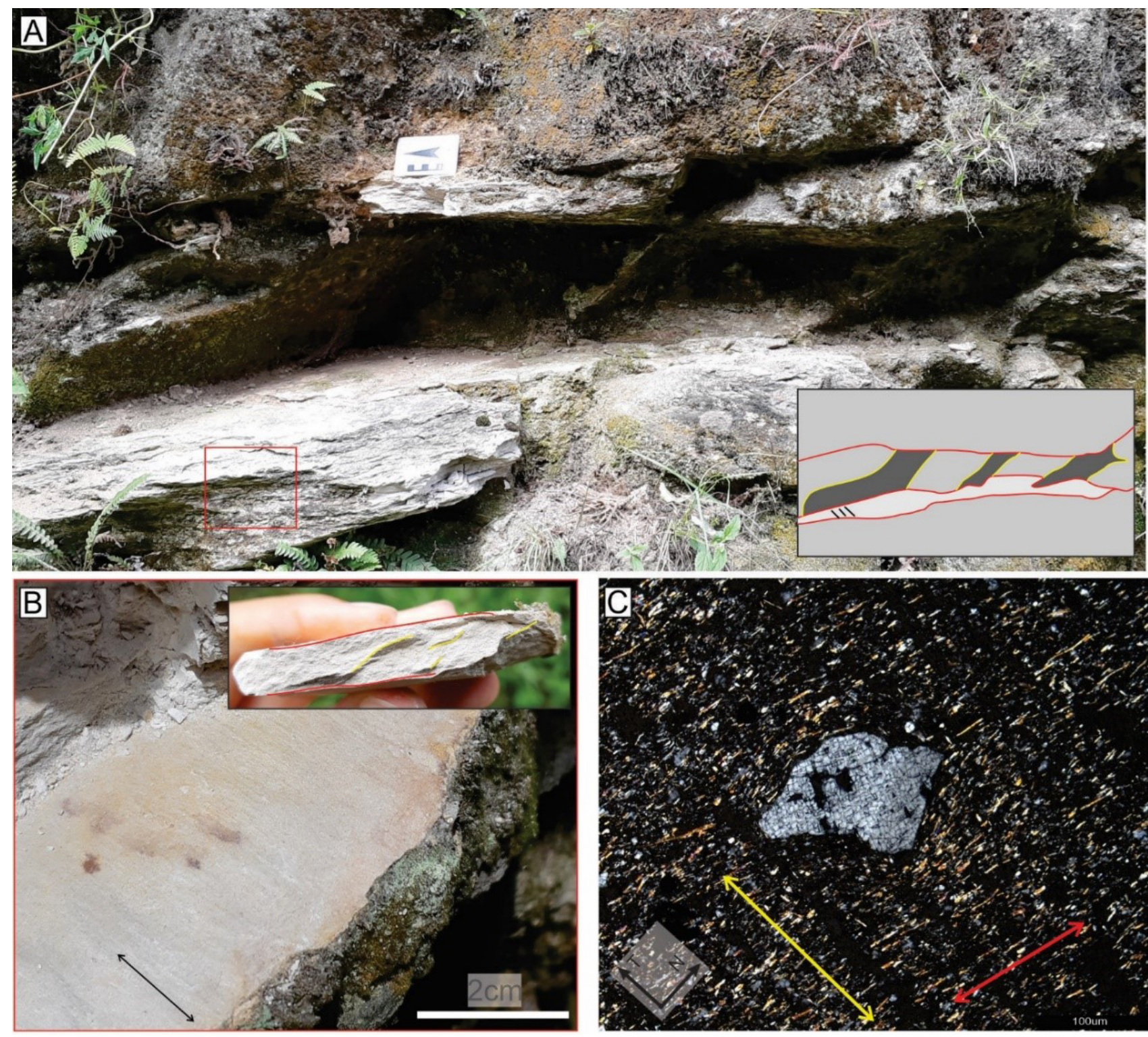

Figura 11 - Duas direções de foliações em diferentes escalas. (A) Afloramento BN-02, mostrando planos horizontais destacados em vermelho no desenho esquemático e planos oblíquos em amarelo preenchidos com cinza escuro. Linhas pretas no esquema indicam lineação de interseção. Quadrado vermelho indica a posição de B. (B) Lineações de interseção (seta preta) em plano com brilho sedoso. Detalhe de amostra de mão com plano horizontal em vermelho e oblíquo em amarelo. (C) Fotomicrografia da amostra BN02-2, com foliação horizontal (seta vermelha) contornando grão de quartzo e clivagem de fratura (seta amarela) cortando a estrutura preexistente.

Em adição às estruturas deformacionais, feições relacionadas à diagênese também foram identificadas. Estilolitos foram encontrados em ao menos duas amostras, ambas com matriz lamosa, onde foi possível descrever duas orientações distintas da estrutura (Fig. 14A). Contatos côncavo-convexos e suturados entre grãos de quartzo são comuns em arenitos (tanto bem quanto mal selecionados), geralmente naqueles com maior maturidade composicional (Fig. 14B). Grãos corroídos, manchas causadas pela percolação de fluidos ricos em ferro e magnésio, compactação diferencial (Fig. 14C), sobrecrescimento de quartzo (Fig. 14D e E) e dissolução parcial do cimento também foram observados.

\section{Discussão}

\subsection{Micromorfologia}

É nítida a presença de microestruturas e microtexturas nas rochas neopaleozoicas do Grupo Itararé, equivalentes àquelas descritas por diversos autores em sedimentos glaciais quaternários (Fig. 15). A análise mostra, no entanto, que diamictitos macroscopicamente maciços possuem vasta gama de microestruturas, enquanto estruturas macro e mesoscópicas não são necessariamente traduzidas em nível de lâmina. 

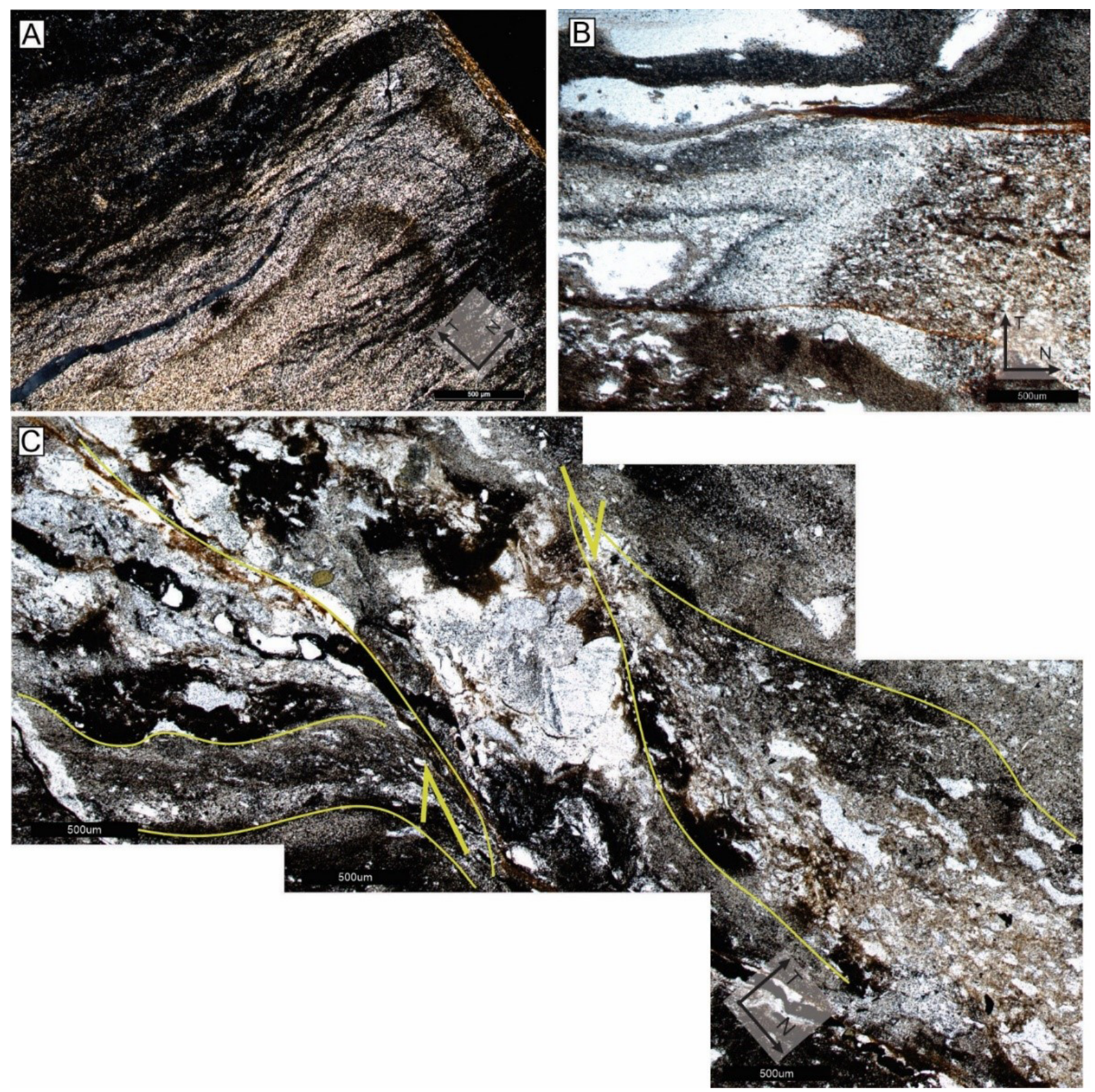

Figura 12 - Fotomicrografias de amostras da amostra BA01. (A) Dobra simétrica. (B) Dobra assimétrica. (C) Dobras de arrasto próximas ao rompimento da camada de areia boudinada.

A deformação pervasiva por cisalhamento observada tanto em diamictitos quanto em arenitos e lamitos é evidenciada pela presença de estruturas rotacionais, alinhamentos de clastos, feições de cisalhamento e "sombras de pressão" (e.g. Baroni \& Fasano, 2006). Tal estilo deformacional também é evidenciado pela presença de clastos cataclasados, gerando componentes angulares e irregulares que podem ser resultado de strain elevado no contato dos grãos ou alta pressão de poros (e.g. Hiemstra \& van der Meer, 1997).

Além disso, plasmic fabrics são visíveis em grande parte das amostras, especialmente as tramas uniastriais, estando ausentes nas rochas que possuem menor porcentagem de argila. Em alguns casos, como em BN02 e
BN03, estas tramas podem ser observadas em amostras de mão a partir da orientação dos minerais micáceos que se concentram em planos bem definidos. A concentração e reorientação de micas em planos é comumente causada por dissolução por pressão em resposta ao stress imposto no material (Fossen, 2010).

\subsection{Influência da diagênese}

Estruturas pós-deposicionais (desenvolvidas durante o soterramento) são representadas principalmente por feições secundárias relacionadas à impregnação de óxidos, assim como dissolução e precipitação de sílica, gerando contatos côncavo-convexos e suturados entre os grãos e sobrecrescimento de quartzo. 

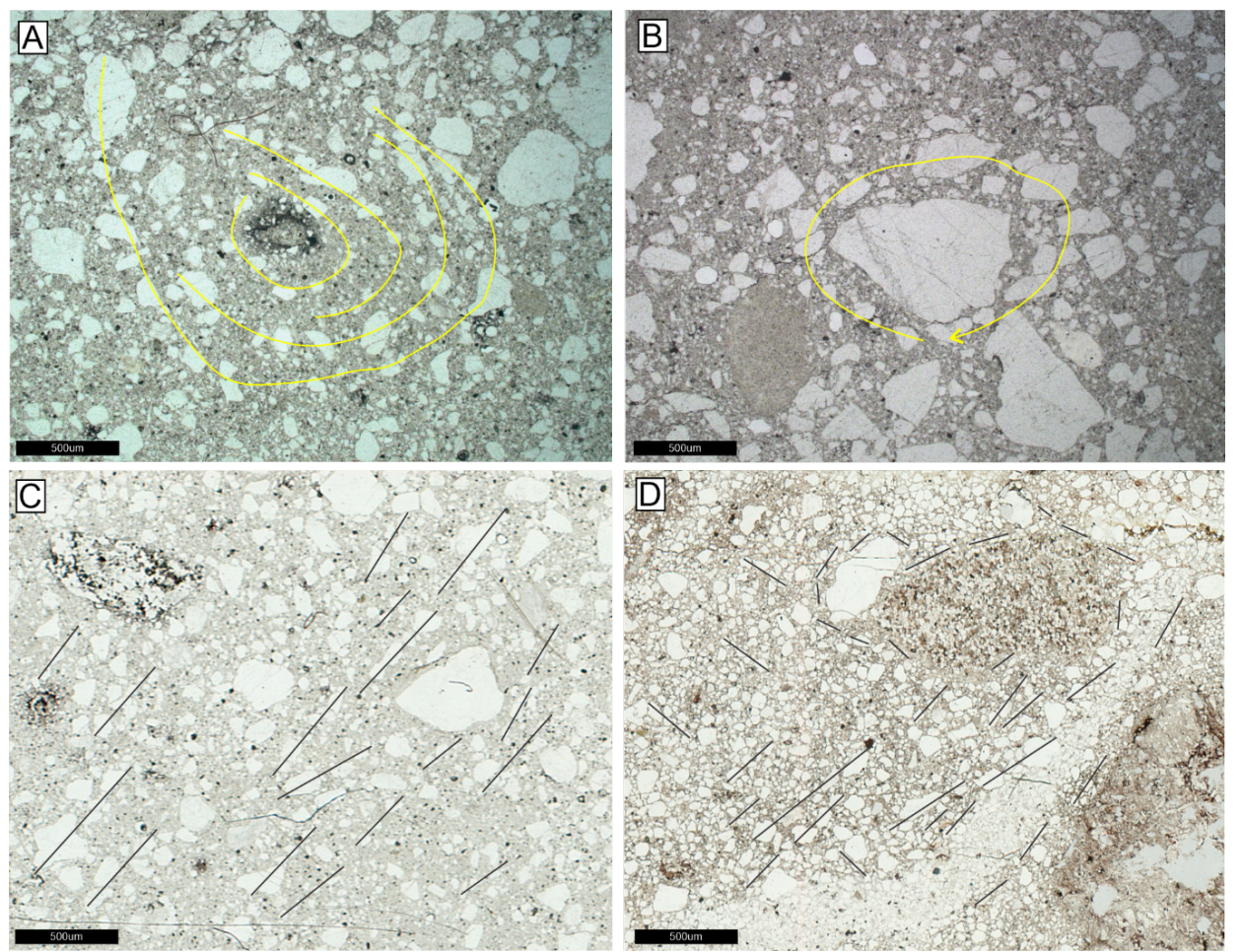

Figura 13 - Fotomicrografias de diamictitos deformados. (A) Grain turbate com diversos "anéis" de grãos orientados na amostra BA11. (B) Grain turbate com apenas um nível de clastos orientados na amostra BA06. (C) Orientação linear de grãos na amostra BA11. (D) Alinhamento de grãos na amostra PU02. Notar como os grãos orientados contornam clastos maiores formando grain turbates na porção superior da imagem.

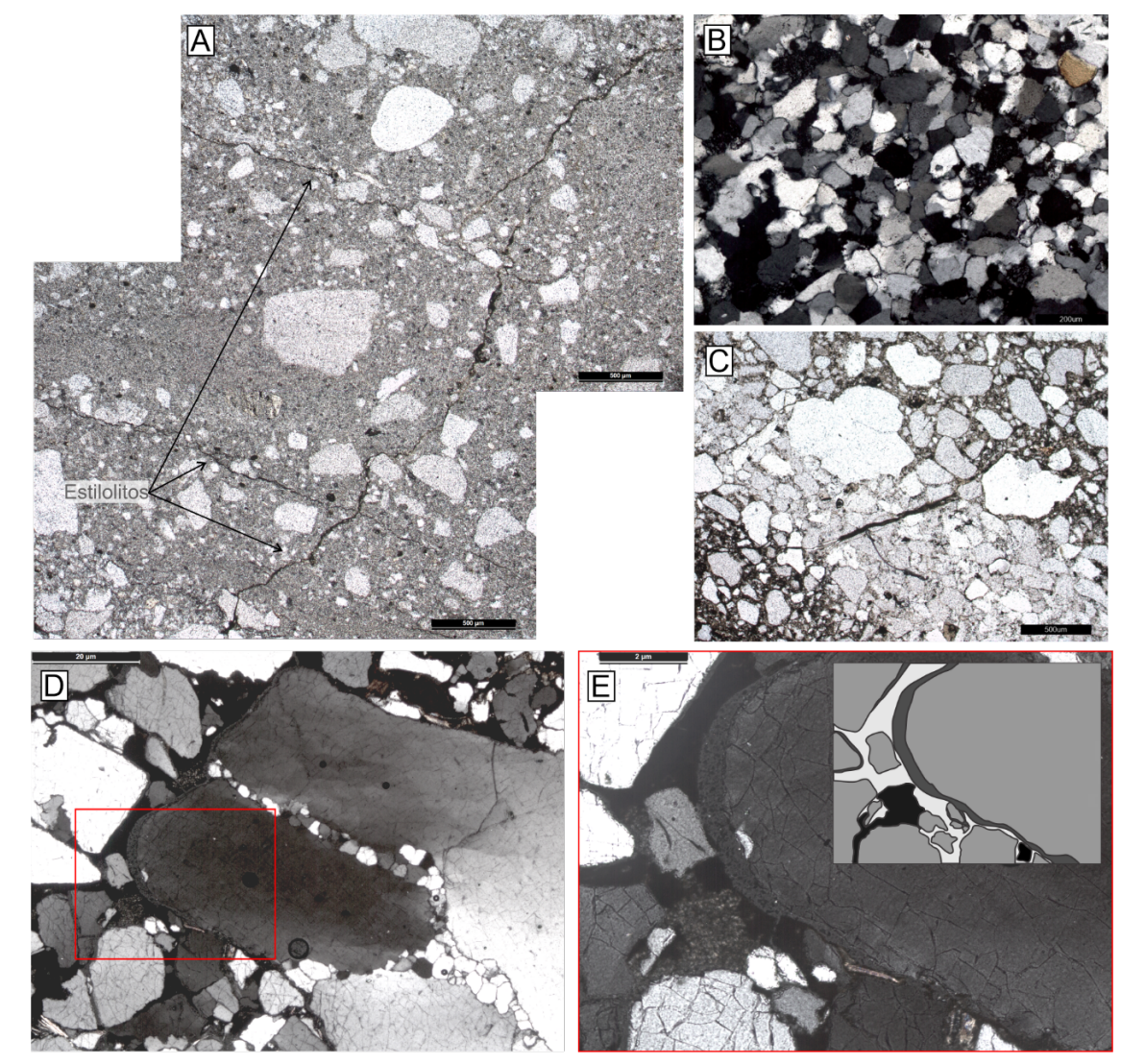

Figura 14 - Feições pós-deposicionais (diagenéticas) observadas em lâmina. (A) Duas direções de estilolitos na amostra BA11. (B) Contatos côncavo-convexos a suturados na amostra BN03. (C) Compactação diferencial entre porções com e sem matriz na amostra PU02. (D) Sobrecrescimento de quartzo em grão de quartzo policristalino da amostra BN02-4. Retângulo vermelho indica detalhe da imagem em (E). 

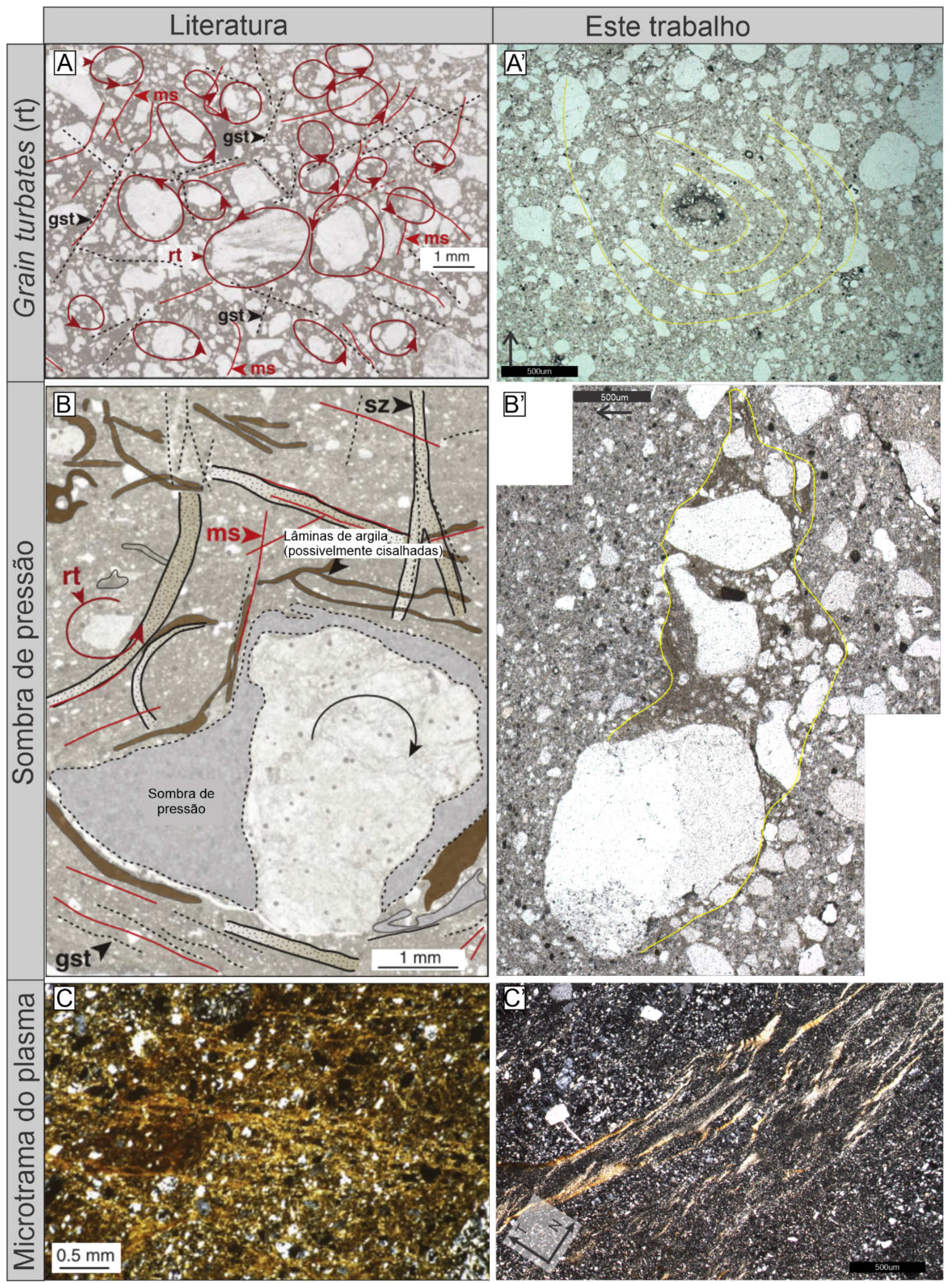

Figura 15 - Comparação entre exemplos da literatura e microfeições observadas neste trabalho. (A) Alinhamento de grãos e grain turbates descritos por Hoedder et al. (2016). (B) Sombra de pressão descrita por Menzies et al. (2016). (C) Plasmic fabrics formando pares tipo S-C descritos por Menzies (1998). (A') (B') (C') exemplos correspondentes encontrados neste trabalho. Setas com indicação para o topo. 
Alsop et al. (2017) apontam a necessidade de cuidado ao interpretar estruturas geradas por deformação em sedimento inconsolidado (Soft-Sediment Deformation Structures; SSD) no registro geológico, uma vez que a compactação e diagênese podem causar alterações e realces nas estruturas preexistentes. Os autores também apontam as incertezas que podem aparecer durante a distinção entre SSD e Hard-rock Deformation (HRD). Os dois processos principais responsáveis por criar ou modificar tramas de SSD são, segundo Farrell \& Eaton (1988), liquefação e compactação. Enquanto a liquefação faz com que os grãos passem por fluxos particulados, alterando lâminas e camadas, a compactação é criada a partir do soterramento, transmitindo deformação pura com encurtamento vertical e realce de tramas sub-horizontais criadas durante a $S S D$.

Maltman (1981) também sugere que, com o aumento da profundidade de soterramento, a diagênese pode "travar" tramas primárias relacionadas com a acomodação ou compactação dos grãos. $\mathrm{O}$ crescimento de novas fases minerais durante a diagênese pode então ser controlado pela orientação da trama sedimentar pré-existente. No entanto, o realce de tramas lineares sub-horizontais não foi observado nas lâminas cujo mapeamento de clastos foi realizado, onde componentes oblíquos são muito mais proeminentes (Garcia, 2020). O crescimento de novas fases minerais orientadas de acordo com a trama pré-existente foi observado em algumas amostras com desenvolvimento avançado de plasmic fabrics. É o caso das amostras BN02, BN03, BA06, BA10 A e B, onde minerais micáceos definindo foliações (ou lineações de estiramento, no caso das duas últimas amostras citadas) são visíveis mesmo macroscopicamente (fig. 11), possivelmente devido ao crescimento tardio de micas e/ou argilominerais originalmente detríticos.

Maltman (1981) sugere que a presença de água intersticial reduz a fricção intergranular, facilitando a rotação dos grãos para a criação de estratificação plano paralela de compactação, ocorrendo precocemente nos primeiros poucos metros de soterramento. Tal afirmação é questionada por Elliot \& Williams (1988), que notaram que tais tramas deformacionais são ausentes de testemunhos de sedimentos modernos que estão a menos de 100 metros de profundidade em relação ao fundo oceânico. Desta forma, há uma ambiguidade no que tange a profundidade necessária de soterramento para a geração de estratificação de compactação.

Uma vez que a compactação por soterramento é aplicada uniformemente nos sedimentos deformados e indeformados, estruturas geradas a partir dela deveriam ser encontradas em ambos os casos. Porém, não é o que se observa na área de estudo (tabela 2). Intervalos não deformados apresentam apenas contatos suturados e dissolução do cimento em alguns casos, sem a formação de foliações de compactação, considerada por autores como Fossen (2010), como uma feição não-deformacional. Falhas normais medidas em rochas do Grupo Itararé demonstraram ângulos menores do que esperados para este tipo de falhamento $\left(60^{\circ}\right.$, Fossen 2010$)$, com mergulhos médios de $30^{\circ}$. Apesar disto, pode ser um indicativo que houve achatamento em detrimento da diagênese.
Ângulos menores são esperados em sedimentos inconsolidados do que em rochas, devido ao fator de fraturamento. A condição crítica na qual o material é fraturado pode ser calculada a partir do coeficiente interno de fricção: em rochas é utilizada uma constante (0.47-0,7, sendo 0,6 o valor mais utilizado), mas para sedimentos o ângulo crítico de repouso é utilizado, no caso $\sim 30^{\circ}$ para areia (Fossen 2010).

\subsection{Glaciotectônica}

A deformação penecontemporânea pode ser encontrada ao longo de grande parte da seção estudada com diferentes estilos, intensidades e escalas. Rosa et al. (2019) sugerem campos altamente concentrados de stress para a deformação, onde o domínio de cisalhamento simples e deformação compressional, somada à ausência de deformação distensional, são característicos da deformação glaciotectônica (Martinsen 1994). Apesar de estruturas serem abundantes em macro escala, a análise cinemática nem sempre é simples de ser conduzida devido à escassez de indicadores (p.ex. estrias e estepes) em falhas. A dificuldade de reconhecer estrias nos planos é amplamente atribuída à composição arenosa das rochas, cuja reologia requer esforço maior para formar e preservar esses tipos de estruturas.

As unidades 1-A e 1-B inferior (CG1 e CG2, Fig. 16A) foram interpretadas por Rosa et al. (2019) como produto de deformação subglacial, atuando como a camada basal deformante (Evans et al. 2006, Menzies et al. 2016) (amostras BA01;10;11;20;21;23, PU02, BN01 - Fig. 16C). Apesar disso, porções da unidade 1-B próximas do afloramento PU-02 exibem estruturas (como dobras suaves a fechadas, falhas normais e inversas) condizentes com cisalhamento puro (McCarroll \& Rijsdijk 2003), indicando que a geleira não passou por cima do sedimento, sendo a deformação possivelmente proglacial, resultando na formação de uma morena de empurrão (Rosa et al. 2019). A unidade 1-B média também apresenta feições deformacionais (dobras de baixa amplitude e cavalgamentos) condizentes a uma morena de empurrão (Rosa et al. 2019), onde truncamentos sub-horizontais que cortam os estratos dobrados são relacionados a sistemas de nappes (van der Wateren, 1995). Apesar de também relacionados a morenas de empurrão, os depósitos da unidade 1-B superior possuem estruturas complexas intercaladas com intervalos pouco a não deformados (fig. 16B). Dobras assimétricas e cerradas relacionadas com cavalgamentos indicam vergência para NW. Diamictitos lamosos cisalhados em contato com níveis areno-cascalhosos, encontrados na saibreira Bassani (BA06, Fig. 9), são interpretados como a "camada basal deformante" (basal deforming layer) (Rosa et al., 2019). São gerados pelo stress transmitido durante a geração da morena de empurrão em uma zona transicional subglacial a glaciomarginal (van der Wateren, 2002).

A identificação de microestruturas em lâmina, por sua vez, não apresenta relação direta com a presença de estruturas deformacionais em macro-escala. Apesar da amostragem ter sido feita preferencialmente onde lineações e/ou cisalhamentos eram visíveis em amostra de mão, a descrição de microfeições depende fortemente da 

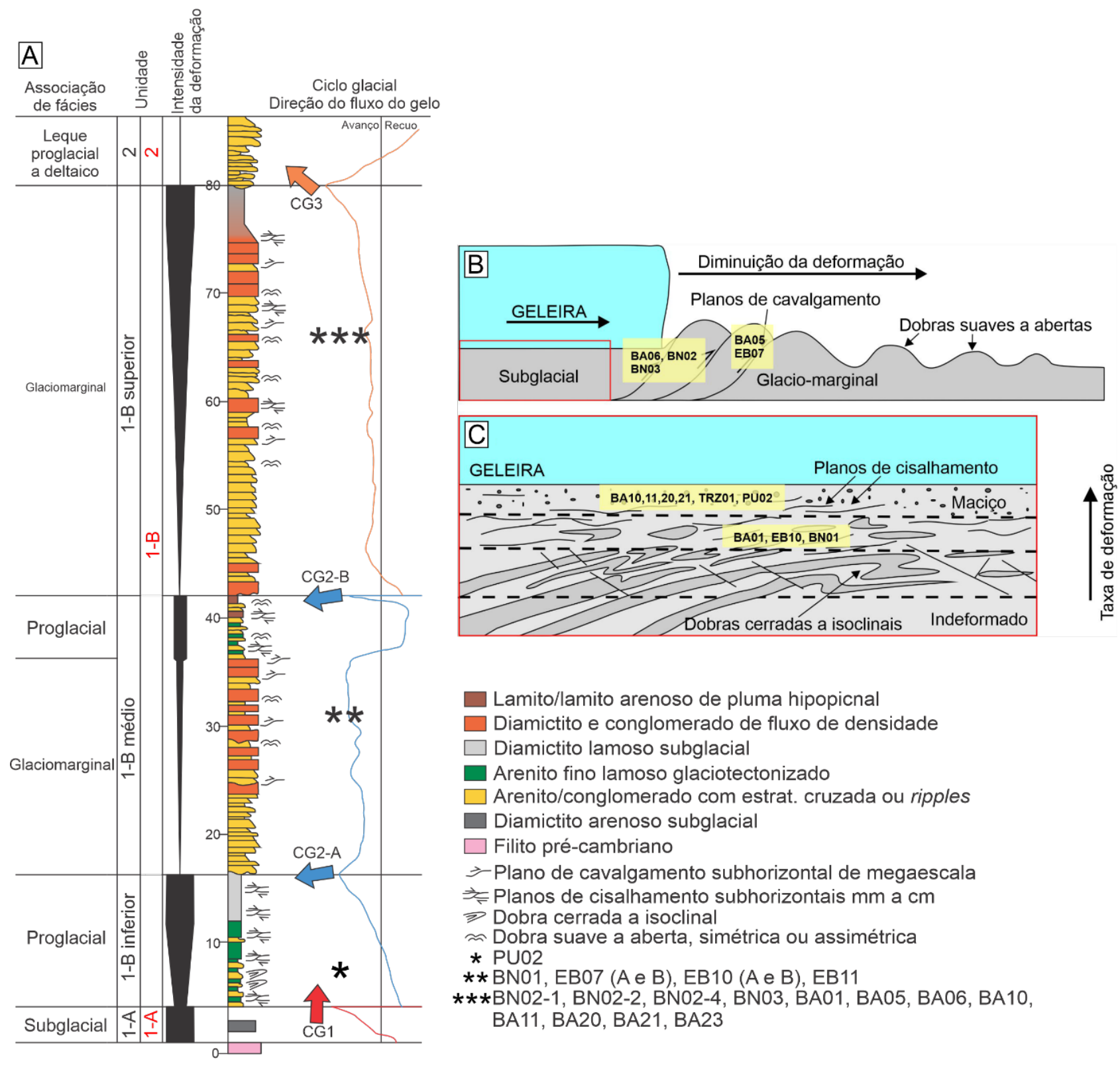

Lamito/lamito arenoso de pluma hipopicnal

Diamictito e conglomerado de fluxo de densidade

$\square$ Diamictito lamoso subglacial

Arenito fino lamoso glaciotectonizado

$\square$ Arenito/conglomerado com estrat. cruzada ou ripples

$\square$ Diamictito arenoso subglacial

Filito pré-cambriano

*-Plano de cavalgamento subhorizontal de megaescala

$\neq$ - Planos de cisalhamento subhorizontais $\mathrm{mm}$ a cm

$\Rightarrow$ Dobra cerrada a isoclinal

$\approx$ Dobra suave a aberta, simétrica ou assimétrica

* PU02

** BN01, EB07 (A e B), EB10 ( $\mathrm{A}$ e B), EB11

***BN02-1, BN02-2, BN02-4, BN03, BA01, BA05, BA06, BA10,

BA11, BA20, BA21, BA23

Figura 16 - A) Posição das amostras laminadas em relação à coluna estratigráfica proposta por Rosa et al. (2019) e modelos dos estilos de deformação proglacial (B) e subglacial (C).

composição da amostra. Isto se deve ao fato de que litotipos mais bem selecionados parecem ter sofrido maiores efeitos da diagênese, resultando em maior grau de compactação e, consequentemente, obliteração de possíveis microestruturas glaciotectônicas. A descrição de microestruturas nesses depósitos mostrou-se mais bem-sucedida em amostras com matriz fina e clastos de diversos tamanhos (diamictitos lamosos), onde evidências da deformação subglacial, tais como microplanos de cisalhamento, sombras de pressão e clastos cisalhados são encontradas (Rosa et al., 2019). Essa mistura imatura de sedimento onde diferentes granulometrias são postas lado a lado permitem que, mesmo sob mesmas condições de stress e pressão de fluidos, diferentes produtos possam ser gerados (van der Meer \& Menzies, 2011).

\section{Conclusões}

O estudo dos estilos deformacionais dos sedimentos depositados durante a glaciação neopaleozoica e deformados por glaciotectonismo provou-se altamente eficiente quando combinados dados de campo e técnicas de microscopia tradicionalmente utilizadas na descrição de depósitos quaternários. A partir desta análise, pode-se concluir que:

- A proposta de van der Meer (1993) é válida como método para análise micromorfológica de depósitos pré-quaternários;

- Nenhuma microestrutura pode ser utilizada individualmente como diagnóstica para diferenciar os diferentes processos de deformação (sub ou proglacial). Mesmo utilizando conjuntos de estruturas, a 
micromorfologia deve ser associada à descrição de fácies e, principalmente, à análise da distribuição vertical e horizontal da deformação em escala de afloramento para determinar a posição do sedimento no momento da deformação em relação ao gelo;

- Fácies macroscopicamente homogêneas e indeformadas podem conter diversas estruturas em microescala. Da mesma forma, a presença de macroestruturas em afloramento ou amostra de mão não necessariamente refletem em deformação em microescala;

- Apesar de gerar algumas feições, tais como dissolução parcial do cimento, contatos côncavo-convexos a suturados e estilolitos, a diagênese não foi um processo que apagou ou obliterou significantemente o registro da deformação em sedimentos inconsolidados. Como a intensidade da diagênese é condicionada pela quantidade de matriz presente na rocha, sendo mais intensa naquelas com pouca ou nenhuma matriz, as estruturas e texturas dos diamictitos analisados sofreram pouca obliteração pelos processos diagenéticos.

\section{Agradecimentos}

Este artigo é produto do mestrado desenvolvido pela primeira autora no Programa de Pós-Graduação em Geologia da Universidade Federal do Paraná, com bolsa da Coordenação de Aperfeiçoamento de Pessoal de Nível Superior (CAPES). A pesquisa foi financiada pelo Conselho Nacional de Desenvolvimento Científico e Tecnológico (CNPq, processos 461650/2014-2, PQ 302842/2017-9, PQ 306780/2019-4). Os autores agradecem ao professor Leonardo Evangelista Lagoeiro pelo empréstimo do scanner para digitalização das lâminas, ao Dr. Emrys Phillips (British Geological Society) pelas discussões e aos revisores pelas valiosas sugestões.

\section{Referências}

ALSOP, G.I., MARCO, S., LEVI, T., WEINBERGER, R. (2017) Fold and thrust systems in Mass Transport Deposits. J. Struct. Geol., 94, 98-115p.

BARONI, C., FASANO, F., (2006). Micromorphological evidence of warm-based glacier

deposition from the Ricker hills tillite (victoria land, Antarctica). Quat. Sci. Rev. 25, 976-992p.

BRUMME, J., HÜNEKE, H., PHILLIPS, E., (2019). Micromorphology and clast microfabrics of subglacial traction tills at the sea cliff Dwasieden: evidence of polyphase syn- and post-depositional deformation. DEUQUA Special Publications 2, 51-60p.

BUSFIELD, M.E., LE HERON, D.P. (2013) Glacitectonic deformation in the chuos formation of northern namibia: Implications for neoproterozoic ice dynamics. Proc. Geol. Assoc., 124, 778-789p.

BUSFIELD, M.E., LE HERON, D.P. (2018) Snowball Earth Under the Microscope. Journal of Sedimentary Research 88 (5): 659-677p.

DENIS, M., GUIRAUD, M., KONATÉ, M., BUONCRISTIANI, J.F. (2010) Subglacial deformation and water-pressure cycles as a key for understanding ice stream dynamics: evidence from the Late Ordovician succession of the Djado Basin (Niger). Int. J. Earth Sci. (Geol Rundsch) 99, 1399-1425p.

ELliOT, C.G, WILliANS, P.F., (1988). Sediment slump structures: a review of diagnostic criteria and application to an example from Newfoundland. J. Struct. Geol., 10, 171-182p.

EVANS, D. J. A., Phillips, E. R., HIEMSTRA, J. F., AUTON, C. A. (2006). Subglacial till: Formation, sedimentary characteristics and classification. EarthScience Reviews 78, 115-176p.

FARRELL, S., EATON, S. (1988) Foliations developed during slump deformation of Miocene marine sediments, Cyprus. J. Struct. Geol., 10, 567-576p.
FOSSEN, H. (2010). Structural Geology. Cambridge University Press, 524 p.

GARCIA, A. M. (2020) Micromorfologia de fácies deformadas do Grupo Itararé e Formação Aquidauana, Paleozoico superior da Bacia do Paraná. Tese de Mestrado. Pós-Graduação em Geologia, Departamento de Geologia, Universidade Federal do Paraná, 76p.

HIEMSTRA, J.F., VAN DER MEER, J.J.M. (1997) Porewater controlled grain fracturing as an indicator for subglacial shearing in tills. Journal of Glaciology 43, 446-454p.

LINCH, L.D., VAN DER MEER, J.J.M., (2015). Micromorphology of ice keel scour in pebbly sandy mud and fine-grained sands: Scarborough Bluffs, Ontario, Canada. Sedimentology 62, 110-129p.

MALTAMN, A. J. (1981) Primary bedding-parallel fabrics in Structural Geology. J. geol. Soc. Lond., 138, 475-483p.

MALTMAN, A. J. (1994) The Geological Deformation of Sediments. Springer, Dordrecht. 368p.

MARTINSEN, O.J. (1994) Mass movements. In: The Geological Deformation of Sediments (Ed. A Maltman), pp. 127-165. Springer, Dordrecht.

MCCAROLL, D., RIJSDIJK, K.F., (2003). Deformation styles as a key for interpreting glacial depositional environments. Journal of Quaternary Science 18, 473-489p.

MENZIES, J. (1998). Microstructures within subglacial diamictons. Relief and deposits of present-day and pleistocene glaciations of the northern hemisphereselected problems. Geography Series, 58, 210-216p.

MENZIES, J., ZANIEWSKI, K. (2003). Microstructures within a modern debris flow deposit derived from Quaternary glacial diamiction - A comparative micromorphological study. Sedimentary Geology, 157(1-2), 31-48p. 
MENZIES, J., VAN DER MEER, J.J., DOMACK, E., WELLNER, J.S., (2010). Micromorphology: As a tool in the detection, analyses and interpretation of (glacial) sediments and man-made materials. Proceedings of the Geologists' Association.

MENZIES, J., (2012). Strain pathways, till internal architecture and microstructures - perspectives on a general kinematic model - a "blueprint" for till development. Quaternary Science Reviews 50, 105$124 \mathrm{p}$.

MENZIES, J., van der Meer, J.J.M., and Ravier, E. (2016) A kinematic unifying theory of microstructures in subglacial tills. Sed. Geology. 244, 57-70p.

PHILLIPS, E., VAN DER MEER, J.J.M., FERGUSON, A. (2011) A new "microstructural mapping" methodology for the identification, analysis and interpretation of polyphase deformation within subglacial sediments. Quat. Sci. Rev., 30, 2570-2596p.

PHILLIPS, E. R., EVANS, D. J. A, VAN DER MEER, J. J. M., LEE, J. R. (2018). Microscale evidence of liquefaction and its potential triggers during soft-bed deformation within subglacial traction tills. Quat. Sci. Rev., 181(i), 123-143p.

REINARDY, B.T., ESCUTIA, C., IWAI, M., JIMENEZESPEJO, F., COOK, C., VAN DER FLJERDT, T., BRINKHUIS, H.I., (2015). Repeated advance and retreat of the East Antarctic Ice Sheet on the continental shelf during the early Pliocene warm period. Palaeogeography, Palaeoclimatology, Palaeoecology 422, 65-84p.

ROSA, E.L.M., VESELY, F.F., ISBELL, J.L., KIPPER, F., FEDORCHUK, N.D., SOUZA, P.A. (2019) Constraining the timing, kinematics and cyclicity of Mississippian-Early Pennsylvanian glaciations in the Paraná Basin, Brazil. Sediment. Geol., 384, 29-49p.
VAN DER MEER, J. J.M. (1993) Microscopic evidence of subglacial deformation. Quat. Sci. Rev., 12, 553-587p.

VAN DER MEER, J.J.M., MENZIES, J., ROSE, J. (2003) Subglacial till: The deforming glacier bed. Quat. Sci. Rev., 22, 1659-1685p.

VAN DER MEER, J.J.M., MENZIES, J. (2011) The micromorphology of unconsolidated sediments. Sed. Geology, 238(3-4), 213-232p.

VAN DER WATEREN, F.M., (1995). Structural geology and sedimentology of push moraines: processes of soft sediment deformation in a glacial environment and the distribution of glaciiotectonic styles. Mededelingen - Rijks Geologische Dienst 54, 167p.

VAN DER WATEREN, F.M., KLUIVING, S.J., BARTEK, L.R., (2000). Kinematic indicators of subglacial shearing. Geological Society Special Publication 176, 261-278p.

VAR DER WATEREN, D.M., (2002). Processes of glaciotectonism, in: Modern and Past Glacial Environments. Elsevier,. 417-443p.

VAUGHAN-HIRSCH, D.P., PHILLIPS, E., LEE, J., HART, J.K., (2013). Micromorphological analysis of poly-phase deformation associated with the transport and emplacement of glaciotectonic rafts at West Runton, north Norfolk, UK. Boreas 42, 376-394p.

VESELY, F.F., TRZASKOS, B., KIPPER, F., ASSINE, M.L., SOUZA, P.A. (2015) Sedimentary record of a fluctuating ice margin from the Pennsylvanian of western Gondwana: Paraná Basin, southern Brazil. Sediment. Geol., 326, 45-63p. 